\title{
LAS ENCUADERNACIONES MUDÉJARES DE LACERÍAS CON MOTIVOS CENTRALES EN LA CATEDRAL DE TOLEDO ${ }^{1}$
}

\author{
Antonio Carpallo Bautista* \\ Facultad de Ciencias de la Documentación. Universidad Complutense de Madrid. \\ Esther Burgos Bordonau** \\ Facultad de Ciencias de la Documentación. Universidad Complutense de Madrid.
}

Resumen: Dentro de la historia de la encuadernación española destaca el florecimiento del estilo mudéjar entre los siglos XIII y XVI, sobre todo en la península ibérica, sobresaliendo los trabajos realizados en algunas ciudades como Toledo. La Biblioteca Capitular de la Catedral de Toledo dispone uno de los grupos más importantes de España, cuantitativa y cualitativamente, aunque su estado de conservación no es el más adecuado en muchos de los ejemplares. El presente trabajo pretende estudiar y analizar los diferentes tipos de encuadernaciones mudéjares con lacerías, tipo de decoración muy propio de ciudades como Toledo, Salamanca y Barcelona. Se han estudiado las estructuras decorativas y los elementos artísticos empleados, las técnicas de decoración y de construcción, así como los materiales utilizados en la elaboración, con lo que hemos podido establecer el origen o procedencia de cada encuadernación en función de la estructura decorativa, de los motivos decorativos individuales, de las filigranas de las guardas originales y del tipo de cabezadas.

Palabras clave: Estilo mudéjar; lacerías; encuadernación artística; Catedral de Toledo; Toledo.

Title: THE MUDÉJAR BOOKBINDINGS WITH INTERLACES OF THE CATHEDRAL OF TOLEDO.

Abstract: The Mudejar style between the thirteenth and sixteenth centuries in the Iberian Peninsula is specially remarkable, within the history of the Spanish bookbinding, outstanding some of the works done in the city of Toledo. The Capitular Library of Toledo's Cathedral has one of the most important collections qualitatively and quantitatively speaking, though its state of preservation is not the best one in many of the items. This work pretends to study and analize the different kinds of mudéjar bookbindings with interlaces, a typical style of decoration of cities like Toledo, Salamanca and Barcelona. A study of the decorative structures, artistic elements, tecniques of decoration and construction has been done as well as the materials used for their making. With all these elements we have been able to establish the origin of each bookbinding according to its decorative structure, the individual decorative motifs, the watermark of the original flyleaves and the kind of tops.

*acarpallo@eubd.ucm.es
** eburgos@pdi.ucm.es

Recibido: 01-11-2011; 2 2avisión: 30-01-2012; aceptado: 08-02-2012.

CARPALLO BAUTISTA, A. y BURGOS BORDONAU, E. Las encuadernaciones mudéjares de lacerías con motivos centrales en la Catedral de Toledo. Anales de Documentación, 2012, vol. 15, $\mathrm{n}^{\mathrm{o}} 1$. http://dx.doi.org/10.6018/analesdoc.15.1.138811. 
Keywords: Mudejar style; interlaces; artistic Bookbinding; Cathedral of Toledo; Toledo.

\section{INTRODUCCIÓN}

En la Península Ibérica se desarrolla entre los siglos XIII al XVI el estilo mudéjar que recoge las novedades introducidas por los árabes, como la utilización de los hierros cordados, que representan la adaptación a la técnica del cuero de aquellos elementos geométricos de trenzados, denominados arabescos, o cordones que llenan toda la tapa, el empleo de nuevas técnicas decorativas, como el estezado ${ }^{2}$, el gofrado ${ }^{3}$ y el dorado, el uso de la piel de cabra o de macho cabrío finamente curtida, denominada cordobán, la sustitución de la madera por el cartón como elemento constitutivo de las tapas y la utilización de la forma o formato de cartera.

El estilo mudéjar, de bella factura de las cubiertas y de influencia orientalizante en la decoración, es uno de los más afamados internacionalmente. Algunos investigadores han tratado de realizar una clasificación de las estructuras decorativas de este tipo de encuadernaciones como Matilde López Serrano ${ }^{4}$, María Isabel Álvaro Zamora ${ }^{5}$ o Julia Méndez Aparicio ${ }^{6}$ con encuadernaciones de bandas u orlas rectangulares, con motivo central, con rectángulo partido, heráldicas, gótico-mudéjar y de lacerías.

Este último grupo es el objetivo de nuestro estudio en el que importantes investigadores españoles como Francisco Hueso Rolland ${ }^{7}$ y Ramón Miquel y Planas ${ }^{8}$, durante el primer tercio del siglo XX, ya habían realizado una breve clasificación de las encuadernaciones mudéjares de lacerías. Esta clasificación la compone un primer modelo denominado toledano, caracterizado por un rosetón central, que se forma mediante una cinta que va trazando diversas estrellas combinadas, además de un encuadramiento llevado a cabo también por una cinta, finalizando la decoración con el relleno con pequeños hierros cordiformes en los espacios vacíos y en ocasiones, pequeños punteados, dejando el lomo marcado con líneas rectas o cruzadas con algún pequeño hierro, todo estampado en seco o gofrado. El segundo grupo es el denominado salmantino, caracterizado por composiciones de tracerías formadas por rectángulos y cuadrados enlazados que se repiten por la parte central de las tapas, decorando los espacios libres con pequeños hierros cordiformes. El tercer modelo es el denominado gótico-mudéjar o catalán-aragonés, caracterizado por uno o dos grandes recuadros trazados con estampaciones de lacería que encuadran la cubierta, seguida de círculos centrales lobulados, rombos y cuatrilóbulos, dejando el espacio central libre para la estampación de un motivo heráldico o signos de propiedad. También Juan Ainaud Lasarte determinó otros grupos regionales de encuadernaciones mudéjares de lacerías en ciudades como Toledo, Barcelona, Valencia, Zaragoza, Tarazona y Salamanca.

La Biblioteca Capitular de la Catedral de Toledo custodia un grupo de encuadernaciones mudéjares, del tipo denominado de lacerías, donde destaca su belleza y el trabajo minucioso formado por cintas de dos filetes que se entrecruzan, algunas de ellas realizadas mediante la técnica del repujado o relieve, decorando el resto del espacio de la 
cubierta con pequeños hierros, en su mayoría, de cordelillo o cordiformes, estampados mediante la técnica del gofrado. Se han catalogado quince encuadernaciones realizándose una división por la estructura decorativa de las lacerías; el presente trabajo trata de estudiar las encuadernaciones mudéjares de lacerías no del tipo toledano y salmantino, sino las encuadernaciones con estructuras decorativas que dividen la tapa en dos mitades dando lugar a cuadrados, hexágonos y rombos, junto a otras figuras geométricas, cuajadas todas ellas de pequeños motivos mudéjares cordados.

Para la realización de este estudio hemos empleado una ficha dividida en varias áreas: los materiales empleados, las técnicas de construcción, la decoración, donde se incluyen la estructura decorativa, los motivos decorativos, la técnica de decoración y los utensilios empleados, junto al estado de conservación; también se han incluido el estilo decorativo, la época de la encuadernación, el encuadernador o taller, la procedencia y emblemas heráldicos, dimensiones y signatura, junto a una descripción bibliográfica de la obra. La recopilación de estos datos nos ha suministrado la información necesaria para establecer el periodo en el que se realizaron estas encuadernaciones, el estudio de los motivos decorativos y sus estructuras así como las estructuras de construcción nos indican que fueron realizados en talleres toledanos, también nos ha ayudado el estudio de los emblemas heráldicos incluidos en las obras junto con el análisis comparativo que hemos realizado de otras encuadernaciones similares realizadas en Toledo.

\section{DESCRIPCIÓN DE LAS FUENTES}

\subsection{Estructura decorativa con el rectángulo partido}

Autor: Lucio Anneo Seneca

Título: [Quince epístolas]

En la primera de estas cuatro encuadernaciones encontramos una estrella de ocho puntas en cada rectángulo. Es un manuscrito del siglo XV, cuyas dimensiones son $423 \mathrm{X}$ 293 X 85 mm., pertenece al Antiguo Fondo Toledano y su signatura es BCT 10-18 ${ }^{10}$. La encuadernación fue realizada alrededor de 1455.

I. Materiales empleados: Las tapas son de madera recubiertas de piel de color marrón, al igual que el lomo; las guardas son de pergamino y las hojas de respeto de papel verjurado con figura o marca de agua conocida como Carro; el lomo está recubierto de papel verjurado con el título rotulado de forma manuscrita; los nervios son de tiras de badana curtida al alumbre; el núcleo de las cabezadas es de tiras de badana curtida al alumbre rodeado de hilo, y recubierto de hilos de colores morado y verde; los broches son de badana curtida al alumbre y de metal; los refuerzos de las dos tapas y del lomo son de pergamino; los refuerzos de la lomera son de tela; los refuerzos de las contratapas son de papel verjurado; la cartela de la tapa anterior es de papel verjurado. 


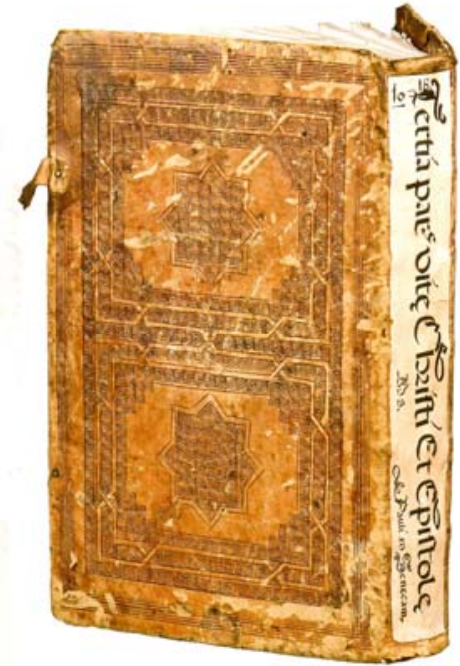

Figura 1. Tapa con el rectángulo interior partido.

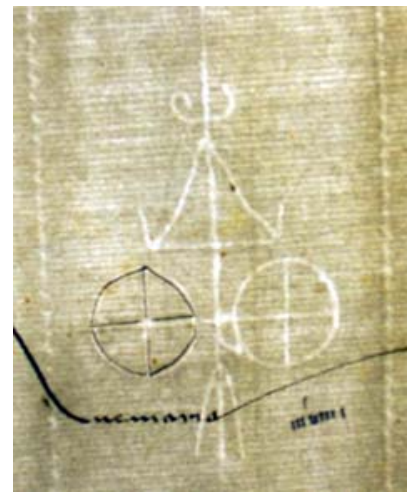

Figura 2. Filigrana conocida como Carro.

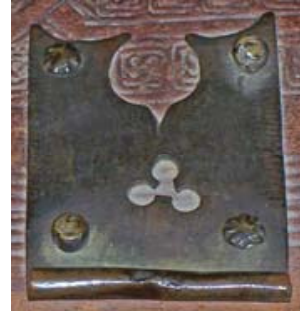

Figura 3. Broches de las tapas.

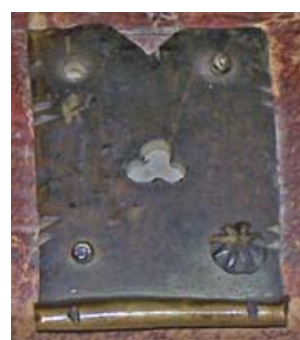

Figura 4. Broches de las tapas.

II. Técnicas de construcción: El cuerpo del libro está unido a las tapas mediante cinco nervios hendidos de tiras de badana curtida al alumbre con un cosido a punto seguido; el lomo está redondeado; las cabezadas, realizadas manualmente, son triples, con un cordoncillo superior y otro inferior, y están unidas a las tapas y a los cuadernillos.

III. Decoración:

III /1. Estructura decorativa: La estructura de las tapas es simétrica y se compone de una orla concéntrica seguida de un trabajo de lacería que divide la tapa en dos rectángulos dentro de los cuales aparece una estrella de ocho puntas.

III /2. Motivos decorativos: La decoración se inicia con un enmarcado de siete filetes paralelos seguida de una orla formada por la repetición de cuadrados en cuyo interior aparece una cruceta de lazo, y que divide la tapa en dos rectángulos; a continuación, y dentro de cada rectángulo, se inicia un trabajo de lacería formado por dos filetes que dan lugar a una cinta continua que se va entrecruzando; los espacios alrededor de la cinta están rellenos de crucetas de lazo dentro de cuadrados. En el interior de los rectángulos aparece una estrella de ocho puntas formada por una cinta de dos filetes; el interior de la estrella está relleno de crucetas de lazo, dejando libre de decoración el espacio exterior de cada estrella. Los utensilios empleados han sido hierros sueltos y la técnica decorativa utilizada ha sido el gofrado. En la tapa anterior aparecen restos de una cartela con inscripciones manuscritas. En la hoja de respeto, junto a la tapa anterior, aparece una figura con un carro. El tejuelo del lomo contiene la leyenda "Tertia pars vite Christi et epistole Pauli ad Senecam Ms.". Las cabezadas están decoradas con el alternado de hilos de seda de colores morado y verde. Los broches que aparecen en la tapa anterior son de diferente tamaño, 
aunque ambos son rectangulares con tres pequeños círculos unidos en el centro que imitan a una hoja de trébol.

IV. Estado de conservación: Su estado es bastante bueno, aunque las tapas están algo deterioradas donde se presentan ciertas rozaduras en las tapas producidas por los herrajes de las encuadernaciones que tiene a ambos lados.

\section{Autor: Guido Baiso}

Título: Archdeacon of Bologna. Archidiaconus super Decreto

La siguiente encuadernación con el rectángulo partido y círculos en cada rectángulo fue realizada en el siglo XV. Este manuscrito perteneció al arzobispo Pedro Tenorio (+1399), actualmente se encuentra en el Antiguo Fondo Toledano, sus dimensiones son 493 X 305 X 105 mm. y su signatura es BCT 12-3.

I. Materiales empleados: Las tapas son de madera recubiertas de piel de color marrón al igual que el lomo; las guardas son de pergamino; los entrenervios están recubiertos de papel verjurado con el título rotulado de forma manuscrita; los nervios son de tiras de piel curtida al alumbre; las cabezadas son de tiras de piel curtida al alumbre e hilos de colores naranja y verde; los broches son de piel marrón y metal; los refuerzos son de pergamino en el lomo y en la guarda.
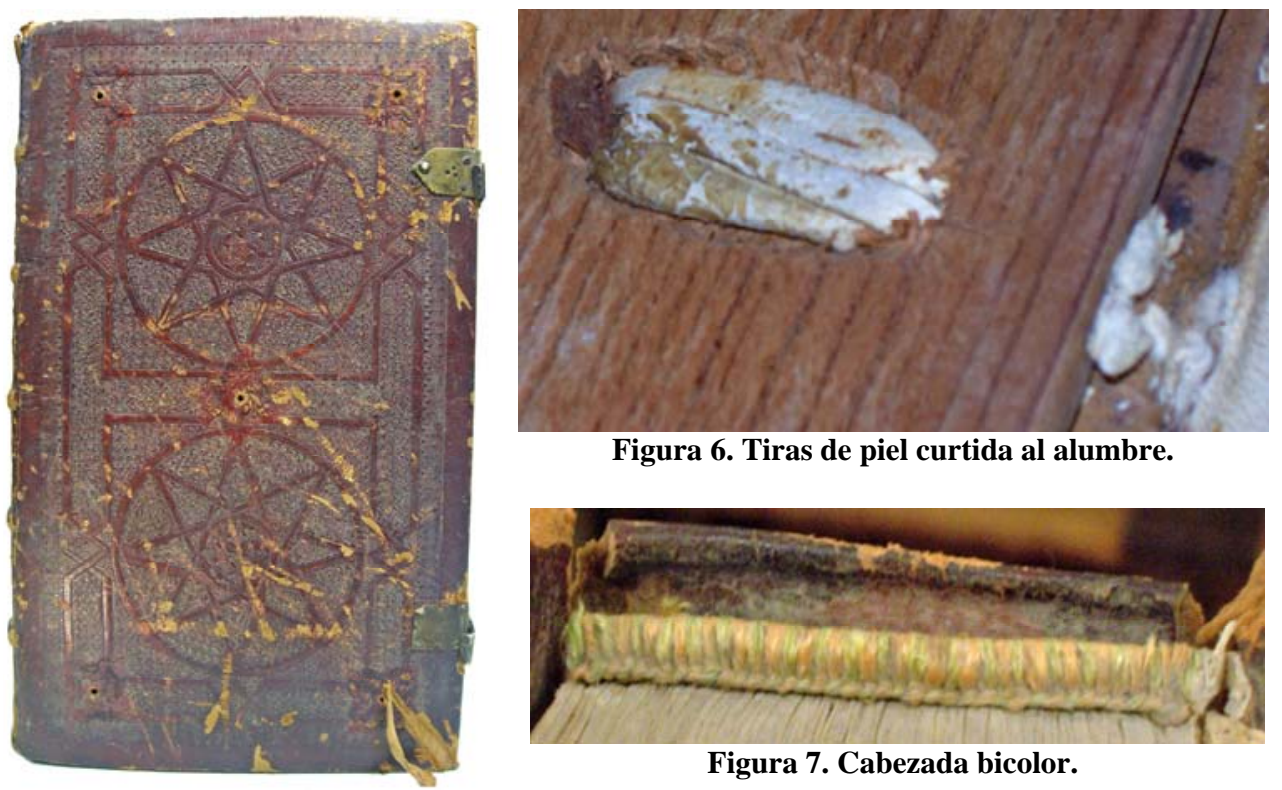

Figura 6. Tiras de piel curtida al alumbre.

Figura 5. Tapa con el rectángulo

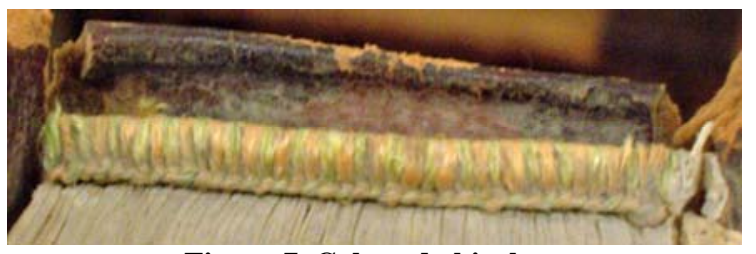

Figura 7. Cabezada bicolor. partido.

II. Técnicas de construcción: El cuerpo del libro está unido a las tapas mediante cinco nervios hendidos de tiras de piel curtida al alumbre, con un cosido a punto seguido; el 
lomo está redondeado; las cabezadas, realizadas manualmente, son simples y están unidas a las tapas y a los cuadernillos.

III. Decoración:

III /1. Estructura decorativa: La estructura de las tapas es simétrica y se compone de una orla seguida de un trabajo de lacería que divide la tapa en dos mitades, apareciendo en cada una de ellas un gran círculo y una estrella de ocho puntas.

III /2. Motivos decorativos: La decoración se inicia con una orla concéntrica de lazos simples cordiformes redondeados con una flor de lis en su interior; a continuación se inicia un trabajo de lacería formado por dos filetes paralelos que dan lugar a una cinta continua que se va entrecruzando. En los espacios libres, y alrededor de la cinta, se estampan multitud de bastoncillos cordiformes rectos y algunos curvos, junto a pequeños circulillos; el espacio libre donde las cintas se entrecruzan está relleno de pequeños circulillos. En cada uno de los dos rectángulos, formados por el trabajo de lacería, se estampa un gran círculo en cuyo interior aparece una estrella de ocho puntas, y un círculo más pequeño en el centro de la estrella. Tanto el círculo, la estrella y el pequeño círculo central están formados por dos filetes que dan lugar a una cinta continua. El espacio libre, tanto en el interior como en el exterior, del gran círculo, y en el interior de la estrella de ocho puntas están ornamentados por multitud de bastoncillos cordiformes rectos y algunos curvos, junto a pequeños circulillos; el interior del círculo central está ornamentado por rombos de lados cóncavos con una pequeña flor en su interior. Los utensilios empleados han sido hierros sueltos y la técnica decorativa utilizada ha sido el gofrado. Las cabezadas están decoradas con el alternado de hilos de seda de colores verde y naranja. Los broches son diferentes, solo el superior contiene tres pequeños círculos que imitan una hoja de trébol.

IV. Estado de conservación: Su estado no es bueno debido a las rozaduras producidas en su actual ubicación ya que comparte estante con otras encuadernaciones que contienen broches y bollones; en la parte superior de la tapa posterior aparecen varios agujeros que posiblemente sean de una cadena; en ambas tapas aparecen cinco agujeros, cuatro en las esquinas y uno central, posiblemente de bollones o clavos de cabeza redonda; las dos tapas contienen numerosas rozaduras y roturas de piel.

Autor: Gregorio IX (1227-1241), papa

Título: [Liber extra, con la glosa ordinaria al margen]

La tercera encuadernación está decorada con una estructura de rectángulo partido y lacerías con estrellas de ocho puntas y estrellas de seis puntas. Es una copia de finales del siglo XIV y con una inscripción manuscrita al final de 1524; también en el folio I hay una nota de un poseedor llamado Luis de Villaquirán, con su firma autógrafa, donde afirma que estudió Derecho en 1469. La encuadernación fue realizada en el siglo XV, actualmente pertenece al Antiguo Fondo Toledano, sus dimensiones son 452 X 275 X 107 mm. y su signatura es BCT 4-8.

I. Materiales empleados: Las tapas son de madera recubiertas de piel de color marrón, al igual que el lomo; las guardas son de pergamino; el lomo está recubierto de papel verjurado con el título rotulado de forma manuscrita; los nervios son de tiras de badana curtida al alumbre; los núcleos de las cabezadas son de tiras de badana curtida al alumbre, 
rodeadas de hilo y recubiertas de hilos de seda de colores naranja y verde; los broches son de metal y las manecillas de badana curtida al alumbre y metal; los refuerzos del lomo son de papel.

II. Técnicas de construcción: El cuerpo del libro está unido a las tapas mediante cuatro nervios hendidos de tiras de badana curtida al alumbre, con un cosido a punto seguido; el lomo es recto; las cabezadas, realizadas manualmente, son simples con nudo superior e inferior, y están unidas a las tapas y a los cuadernillos; la lomera no está unida al lomo lo que favorece la apertura del libro.

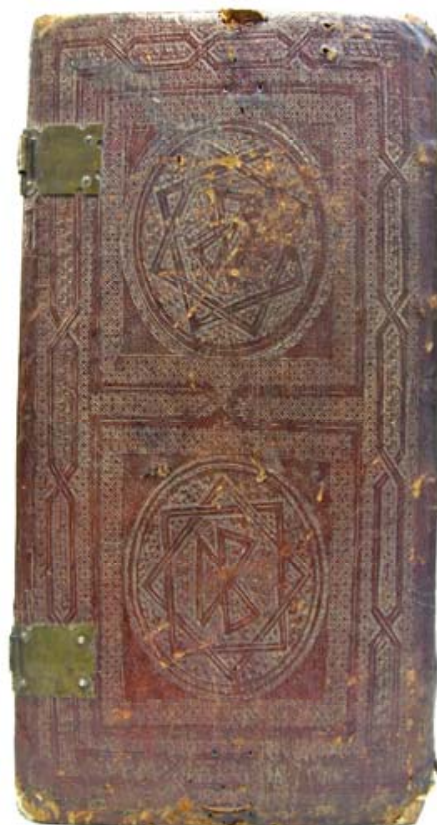

Figura 8. Tapas con el rectángulo partido.

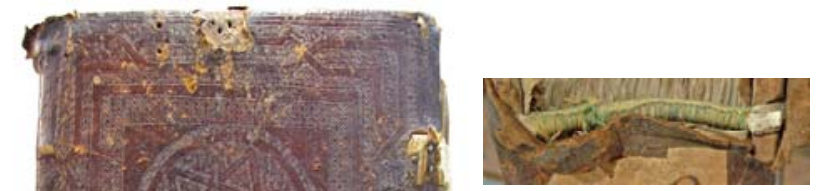

Figura 10. Cabezada bicolor.

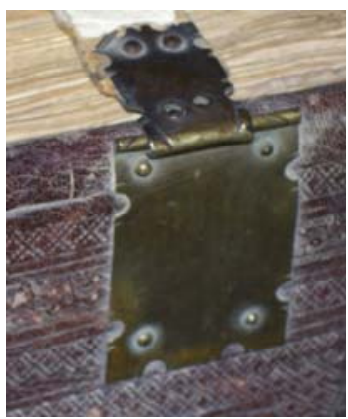

Figura 11. Broche de metal.

\section{Decoración:}

III /1. Estructura decorativa: La estructura de las tapas es prácticamente simétrica y se compone de una orla concéntrica y un trabajo de lacería que divide la tapa en dos rectángulos en cuyo interior aparecen dos grandes círculos rellenos de hierros sueltos.

III /2. Motivos decorativos: La decoración se inicia en la parte superior de la tapa anterior con dos filetes y una hilera, flanqueada por un filete a cada lado, de lazos simples cordiformes redondeados con un pequeño punto en su interior. El resto de esta orla en ambas tapas está decorada por la repetición de una curva o aspa; a continuación, mediante la estampación de tres filetes paralelos, se forma una cinta continua que se entrecruza formando un trabajo geométrico de lacería. Los espacios libres dejados por la cinta, están 
rellenos, en la zona más externa, por eses inclinadas cordiformes y pequeños circulillos, y hacia el interior de las tapas por curvas o aspas. Los rectángulos, en que están divididas las tapas, tienen un enmarcado de dos hileras de curvas o aspas. El interior de los rectángulos centrales está ornamentado con un gran círculo formado por la repetición de eses inclinadas, y cada uno con una estructura decorativa diferente. La decoración del círculo superior de la tapa anterior se forma mediante la repetición de eses inclinadas cordiformes junto a pequeños circulillos; en el interior aparecen dos triángulos formados por una cinta de tres hilos paralelos que se entrecruzan, formando una estrella de seis puntas en cuyo interior aparece una cinta de dos hilos que se entrecruza dando lugar a tres pequeños triángulos unidos por uno de sus vértices; los espacios libres dejados por las cintas están rellenos de eses inclinadas cordiformes y pequeños circulillos. El círculo inferior de la tapa anterior está decorado mediante la repetición de eses inclinadas cordiformes junto a pequeños circulillos; en el interior aparecen dos triángulos de tres hilos paralelos que da lugar a dos grandes triángulos entrecruzados que forman una gran estrella de seis puntas, junto a otras tres cintas de tres filetes paralelos que se entrecruzan; los espacios libres dejados por las cintas están rellenos de eses inclinadas cordiformes y pequeños motivos decorativos. En la tapa posterior el círculo superior se forma por la repetición de eses inclinadas cordiformes junto a pequeños circulillos, seguidas hacia el interior, por una cinta de tres hilos paralelos; en el interior aparecen dos cuadrados formados por una cinta de tres hilos paralelos, que se entrecruzan formando una estrella de ocho puntas, en cuyo interior aparece otra cinta de tres hilos paralelos que se entrecruza dando lugar a tres pequeños triángulos unidos por uno de sus vértices; los espacios libres dejados por las cintas están rellenos de eses inclinadas cordiformes y pequeños circulillos. La decoración del rectángulo inferior de la tapa posterior se basa dos círculos formados por pequeños circulillos, dejando una cinta de dos filetes entre medias; la decoración interior es similar a la del círculo superior de esta misma tapa, al igual que la decoración de los espacios libres. Los utensilios empleados han sido hierros sueltos y la técnica decorativa utilizada ha sido el gofrado. Las cabezadas están decoradas con el alternado de hilos de seda de colores verde y naranja. Los nervios están decorados con un hilo horizontal gofrado que acentúa el empleo de nervios hendidos. Los broches metálicos, con forma cuadrangular, carecen de motivos relevantes decorativos.

IV. Estado de conservación: Su estado es bueno, aunque presenta restos de broches en la parte inferior y superior de ambas tapas, además de rozaduras y pérdidas de piel por toda la encuadernación, debido a los broches y herrajes de las encuadernaciones que tiene a ambos lados.

Autor: Santo Tomás de Aquino

Título: [Suma de fe contra los gentiles]

La cuarta encuadernación decorada con una estructura de rectángulo partido y lacerías con estrellas de ocho puntas y estrellas de seis puntas contiene una obra manuscrita copiada entre finales del siglo XIV y primeros del XV. La encuadernación fue realizada también a finales del siglo XIV o primeros del XV, pertenece al Antiguo Fondo Toledano, sus dimensiones son 225 X 157 X $77 \mathrm{~mm}$. y su signatura es BCT 19-17. 
I. Materiales empleados: Las tapas son de madera biselada recubiertas de piel de color marrón, al igual que el lomo; las guardas son de pergamino; los nervios son de tiras de piel curtida al alumbre; el núcleo de las cabezadas es de tiras de piel curtida al alumbre rodeadas de hilo blanco, y recubiertas de hilos de seda de color verde; los refuerzos del lomo son de tela; los broches son de metal y de badana; los entrenervios están recubiertos de papel verjurado blanco con el título rotulado de forma manuscrita; la cartela de pergamino de la tapa posterior también contiene el título rotulado de forma manuscrita.

II. Técnicas de construcción: El cuerpo del libro está unido a las tapas mediante cinco nervios hendidos de tiras de piel curtida al alumbre, con un cosido a punto seguido; el lomo está redondeado; las cabezadas están unidas a los cuadernillos y a las tapas; el corte delantero carece de cejas.

III. Decoración:

III /1. Estructura decorativa: La estructura de las tapas es simétrica y se compone dos orlas concéntricas, la segunda dividida en dos partes, dentro de las cuales aparecen, por un lado dos triángulos entrecruzados que dan lugar a una estrella de seis puntas, y por otra parte dos cuadrados entrecruzados que dan lugar a una estrella de ocho puntas.

III /2. Motivos decorativos: La decoración se inicia con un enmarcado exterior de dos hilos, seguida de una entrecalle libre de decoración, solo decorada por dos hilos en las esquinas que unen un enmarcado exterior con la primera orla. La primera orla se compone de dos filas de aspas rectas en la zona cercana al lomo y a la delantera, y de una fila de aspas rectas en la zona cercana a la cabeza y pie, junto a cuatro pequeños punteados y otro mayor en el centro como relleno; a continuación se dispone de dos hilos que dan lugar a una cinta que se entrecruza formando un trabajo de lacería. La segunda orla, que se divide en dos cuadrados, está formada por dos filas de pequeñas aspas rectas y pequeños punteados como relleno. El interior de cuadrado superior de la tapa anterior está decorado por una cinta de dos hilos que forman dos triángulos entrecruzados dando lugar a una estrella de seis puntas; la decoración interior y exterior de la estrella está compuesta por aspas rectas junto a cuatro pequeños punteados y otro mayor en el centro como relleno. El cuadrado inferior de la tapa anterior está decorado por una cinta de dos hilos que forman dos cuadrados entrecruzados dando lugar a una estrella de ocho puntas; la decoración interior está compuesta por aspas rectas junto a cuatro pequeños punteados y otro mayor en el centro como relleno, y la exterior por pequeñas aspas rectas y pequeños punteados como relleno. El cuadrado superior de la tapa posterior está decorado por una cinta de dos hilos que forman dos cuadrados entrecruzados dando lugar a una estrella de ocho puntas; la decoración interior está compuesta por pequeñas aspas rectas y pequeños punteados como relleno, y la exterior por aspas rectas junto a cuatro pequeños punteados y otro mayor en el centro como relleno. El cuadrado inferior de la tapa posterior está decorado por una cinta de dos hilos que forman dos triángulos entrecruzados dando lugar a una estrella de seis puntas; la decoración exterior e interior está formada por pequeñas aspas rectas y pequeños punteados como relleno. En la parte superior de la tapa posterior aparecen restos de una cartela con inscripciones manuscritas. Los utensilios empleados han sido hierros sueltos y la técnica decorativa utilizada ha sido el gofrado. Los entrenervios del lomo están decorados con una paleta de dos hilos a cada lado de los nervios y en el centro de los entrenervios con la misma paleta de dos hilos que se 
entrecruzan formando pequeños rombos. Las cabezadas están decoradas con el alternado de hilo de seda de color verde. Los broches metálicos en la tapa posterior tienen forma de triángulo; en la parte metálica de las manecillas de badana aparece un pequeño rombo en el centro.

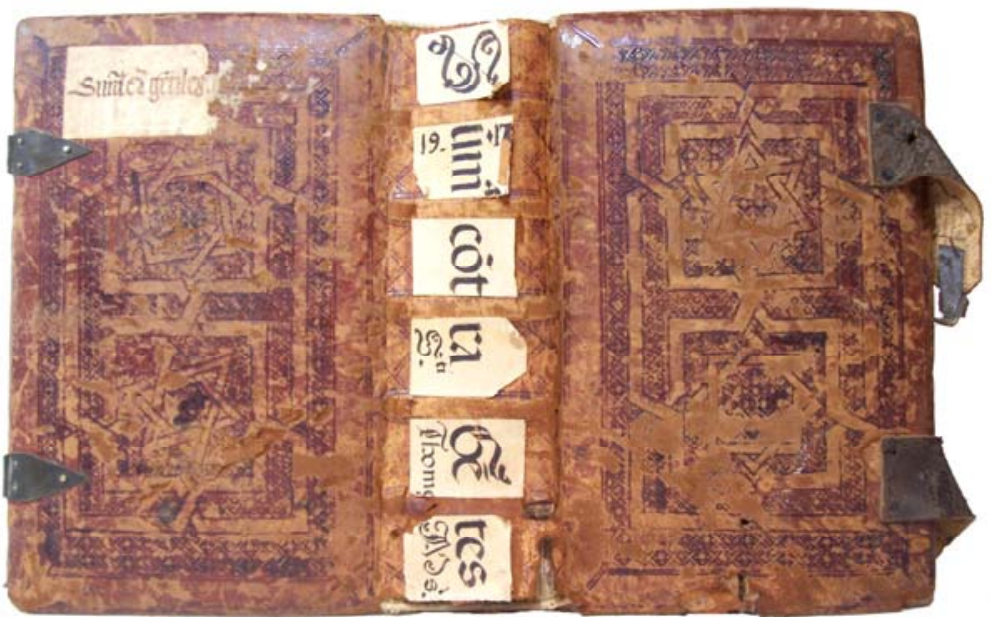

Figura 12. Tapas con estrellas de seis y ocho puntas.

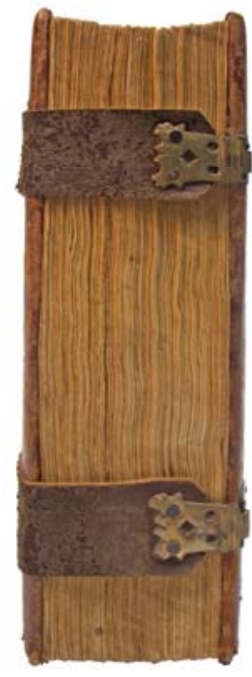

Figura 13. Corte delantero.

IV. Estado de conservación: Su estado es bastante bueno, aunque presenta una rotura de la piel de la tapa anterior, posiblemente producida por el mal uso, junto a varios agujeros, seguramente restos de una cadena, en la parte inferior de la tapa anterior, además de numerosas rozaduras en ambas tapas y lomo debido a las encuadernaciones cercanas.

\subsection{Estructura decorativa con dos cuadrados en el centro}

Las siguientes cinco encuadernaciones están decoradas con una estructura de lacerías con dos cuadrados en el centro, uno en la parte superior y otro en la inferior.

Autor: Alberto Magno (1206-1280)

Título: [Tratado de minerales]

La primera de este grupo de encuadernaciones contiene un manuscrito, copiado entre finales del siglo XIV y finales del XV, de papel de 43 folios a 2 columnas con 45 líneas, con una escritura cursiva. La encuadernación es del siglo XV, pertenece al Antiguo Fondo Toledano, sus dimensiones son 300 X 228 X 30 mm. y su signatura es BCT 17-11.

I. Materiales empleados: Las tapas son de madera recubiertas de piel de color marrón al igual que el lomo; el tejuelo que aparece en la tapa anterior es de papel verjurado con el título rotulado de forma manuscrita; las guardas son de pergamino con el título rotulado 
de forma manuscrita; las hojas de respeto son de papel verjurado crema con una filigrana o marca de agua conocida como Atril; los nervios son de tiras de piel curtida al alumbre; las cabezadas son de tiras de piel curtida al alumbre rodeadas de hilo de lino recubiertos de hilos de colores verde y naranja; los entrenervios estás recubiertos por papel verjurado con el título rotulado de forma manuscrita; los broches de la delantera de las tapas son de metal.

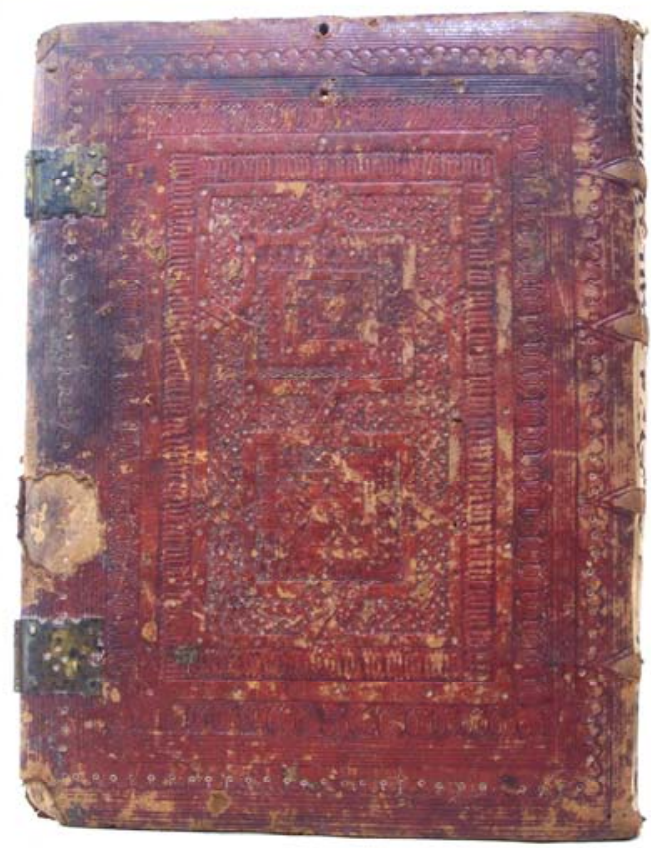

Figura 14. Tapa con dos cuadrados en el centro.

II. Técnicas de construcción: El cuerpo del libro está unido a las tapas mediante cuatro nervios hendidos de tiras de piel curtida al alumbre, con un cosido a punto seguido; el lomo está redondeado; las cabezadas, realizadas manualmente, están unidas a las tapas y a los cuadernillos; el corte delantero carece de ceja.

III. Decoración:

III /1. Estructura decorativa: La estructura de las tapas es simétrica y se compone de tres orlas concéntricas y dos estrellas de ocho puntas en el centro formadas por una decoración de lacerías.

III /2. Motivos decorativos: La primera orla está decorada con arquillos unidos en sus extremos con pequeños circulillos que parecen dorados o pintados, estando rodeado, por el exterior por ocho filetes y siete el interior; la segunda orla está formada por alfardones encadenados; la segunda orla está decorada por una figura parecida a una "M" gótica. Las entrecalles están decoradas con pequeños circulillos que parecen dorados o pintados. El 
rectángulo central está decorado con dos estrellas de ocho puntas formadas por el entrecruzado de una cinta, la cual está decorada en su interior con pequeños circulillos que parecen dorados o pintados; los espacios existentes entre la cinta están igualmente decorados, en la parte exterior de las estrellas, por pequeños bastoncillos cordiformes que se entrecruzan y por lazos simples redondeados en el interior. Los utensilios empleados han sido hierros sueltos y las técnicas decorativas utilizadas han sido el gofrado y posiblemente el dorado o pintado. Las cabezadas están decoradas con el alternado de hilos de seda de colores verde y naranja. Los broches metálicos tienen forma cuadrangular y están decorados con cuatro pequeños circulillos en forma de cruz. Las guardas contienen párrafos jurídicos manuscritos realizados con tinta negra y roja.

IV. Estado de conservación: En líneas generales su estado es bueno, aunque en la parte superior de la tapa posterior aparecen agujeros de broches o cadenas; también hay pérdida de los broches de piel, muy posiblemente desprendidos por su uso.

Título: [Biblia Vulgata latina] Mss. S. XIV

La segunda de este grupo de encuadernaciones fue probablemente realizada por un artesano toledano en el siglo XV; pertenece en la actualidad al Antiguo Fondo Toledano, sus dimensiones son 325 X 234 X $109 \mathrm{~mm}$. y su signatura es BCT 2-7.

I. Materiales empleados: Las tapas son de madera recubiertas de becerro de color marrón rojizo, al igual que el lomo; la tapa posterior contiene restos de una cartela de papel; las guardas son de pergamino; el lomo está recubierto de papel verjurado con el título rotulado de forma manuscrita; los nervios son de tiras de piel curtida al alumbre; el núcleo de las cabezadas es de tiras de piel junto a dos pequeños cordoncillos, uno superior y otro inferior, rodeados de hilo de color blanco y recubiertos de hilos de seda de colores azul y amarillo; los broches son de metal y las manecillas son tiras de piel con las puntas metálicas.

II. Técnicas de construcción: El cuerpo del libro está unido a las tapas mediante siete nervios hendidos de tiras de piel curtida al alumbre, con un cosido a punto seguido; el lomo es recto; las cabezadas, realizadas manualmente, están unidas a las tapas y a los cuadernillos.

III. Decoración:

III /1. Estructura decorativa: La estructura de las tapas es simétrica y está formada por tres orlas concéntricas, dividiéndose la más interna en dos rectángulos, en cuyo interior aparecen otros rectángulos más pequeños separados entre ellos por un trabajo de lacería.

III /2. Motivos decorativos: La decoración se inicia con tres hierros paralelos de dos filetes cada uno, seguidos de una primera orla ornamentada con lazos simples cordiformes redondeados con una flor de lis en su interior. La segunda orla está formada por lazos simples cordiformes en ángulo con una pequeña flor en su interior. La entrecalle entre la primera y segunda orla está libre de decoración y está formada por dos hierros de dos filetes cada uno. La tercera orla está formada, al igual que la segunda, por lazos simples cordiformes en ángulo con una pequeña flor en su interior, que dividen la orla en dos rectángulos iguales. A partir de este momento las entrecalles están formadas por dos filetes que dan lugar a una cinta que se entrecruza creando un trabajo de lacería. Los dos espacios entre las cintas que se entrecruzan están rellenos de peltas y dobles circulillos 
punteados. En la tapa posterior aparecen restos de un tejuelo de papel con la inscripción "Biblia Ms.". Los espacios interiores de los dos rectángulos centrales están ornamentados con peltas cruzadas y dobles circulillos punteados. Los utensilios empleados han sido hierros sueltos y la técnica decorativa utilizada ha sido el gofrado. Los nervios están ornamentados con un filete gofrado horizontal que acentúa el empleo de nervios hendidos. Los entrenervios están decorados con una fila de peltas gofradas que se cruzan formando pequeñas cruces. El tejuelo contiene la inscripción "Biblia Ms.". Las cabezadas están decoradas con el alternado de hilos de seda de colores azul y amarillo. Los broches y las manecillas de piel junto a sus puntas metálicas no tienen decoración alguna relevante.

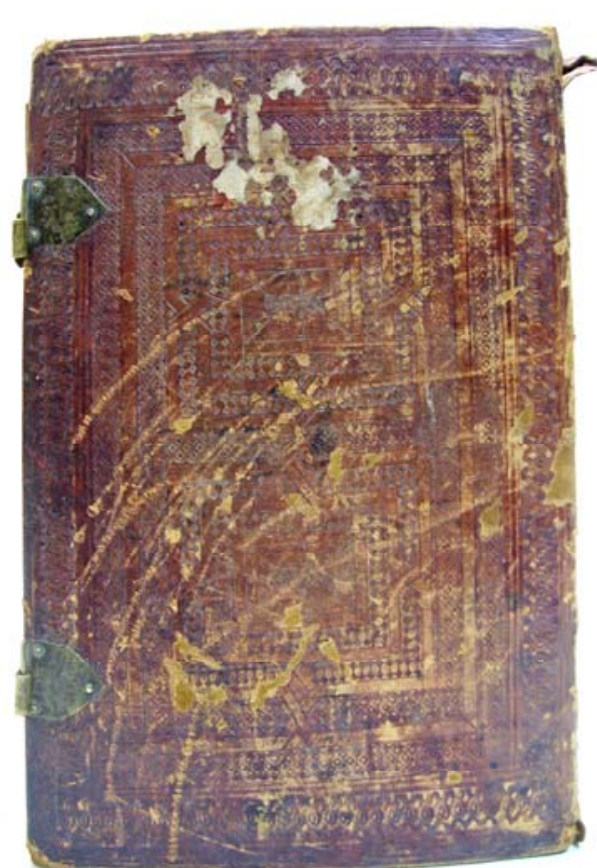

Figura 15. Tapa posterior con dos cuadrados en el centro.

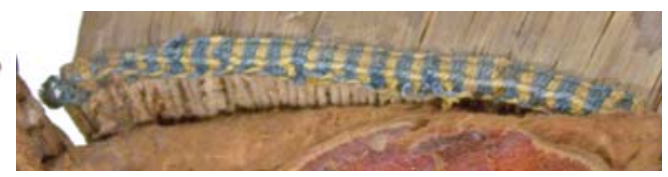

Figura 16. Cabezada bicolor.

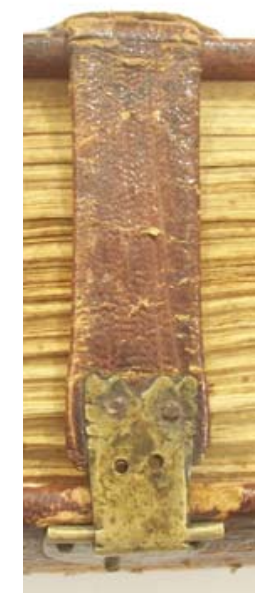

Figura 17. Manecilla de piel y punta de metal.

IV. Estado de conservación: Su estado es bueno en general, aunque encontramos la cabezada deteriorada, seguramente por el mal uso al querer extraer el libro de la estantería tirando de ella, al igual que la tabla de la cubierta anterior, junto a agujeros para las cadenas en la parte superior de la tapa anterior.

Autor: Bonifacio VIII (1294-1303), papa

Título: [Los cinco libros del sexto de las Decretales con glosas] que contiene reglas del Derecho Canónico en 128 hojas de pergamino realizada en el siglo XIV.

La siguiente encuadernación con esta estructura decorativa de dos cuadrados centrales realizados con lacerías, fue realizada muy posiblemente en Toledo en el siglo XV, 
perteneció al arzobispo Don Pedro Tenorio (1376-1399), cuyo escudo aparece en el folio 4, y actualmente se encuentra dentro de Antiguo Fondo Toledano, sus dimensiones son 470 X 290 X 55 mm. y su signatura es BCT 4-12.

I. Materiales empleados: Las tapas son de madera, de $70 \mathrm{~mm}$. de espesor, recubiertas de piel de color marrón, al igual que el lomo; las guardas y las hojas de respeto son de pergamino; los nervios son de tiras de piel; el núcleo de la cabezada superior es de tira de piel e hilos de color amarillo y crema; los entrenervios están recubiertos por papel verjurado con el título rotulado de forma manuscrita; el broche de la delantera de la tapa posterior es de piel y las puntas de metal.

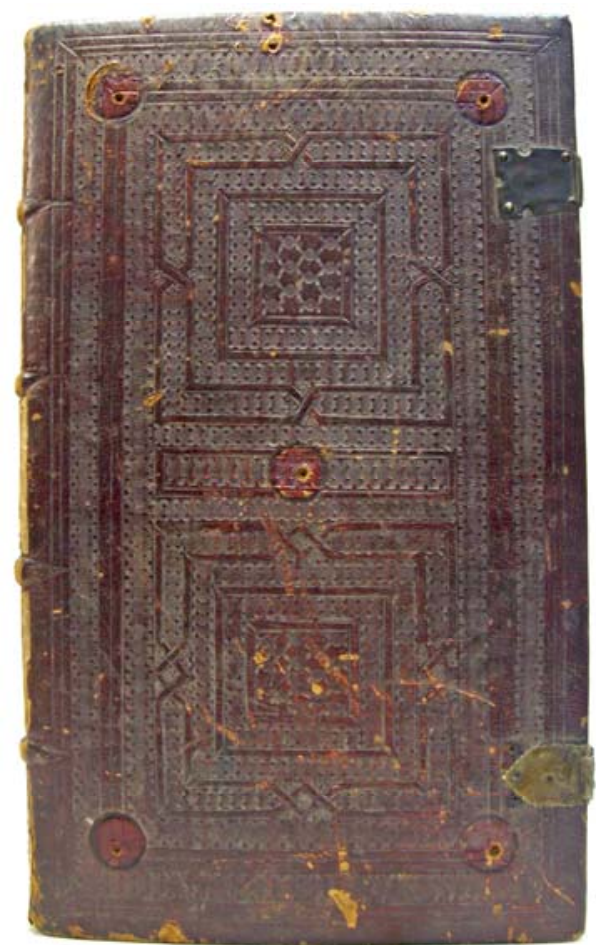

Figura 18. Tapa anterior con dos cuadrados en el centro.

II. Técnicas de construcción: El cuerpo del libro está unido a las tapas mediante cuatro nervios hendidos de tiras de piel curtida al alumbre, con un cosido a punto seguido; el lomo es recto, casi no apreciándose el ceñido de los nervios; las cabezadas, realizadas manualmente, están unidas a las tapas y a los cuadernillos; las tapas carecen de cejas.

III. Decoración:

III /1. Estructura decorativa: La estructura de las tapas es simétrica y se compone de dos orlas concéntricas y dos rectángulos centrales donde aparece un trabajo de lacería, decorando el centro de los rectángulos con hierros sueltos. 
III /2. Motivos decorativos: La decoración se inicia con tres filetes paralelos, seguidas de dos orlas formadas por lazos simples cordiformes redondeados con una flor de lis en su interior; la entrecalle existente entre las dos orlas está formada por tres filetes paralelos. El centro de la tapa se divide en dos rectángulos independientes, uno superior y otro inferior, seguido de un trabajo de lacería mediante la estampación de dos filetes o hilos que forman una cinta continua que se va entrecruzando; los espacios libres dejados por la cinta aparecen rellenos de lazos simples cordiformes en ángulo con una pequeña flor en su interior. La parte central de los rectángulos de cada tapa están ornamentados con una pequeña orla de lazos simples cordiformes en ángulo y una pequeña flor en su interior, seguido de cuatro hileras de lazos simples cordiformes en ángulo, distribuidos de forma ajedrezada. Los utensilios empleados han sido hierros sueltos y la técnica decorativa utilizada ha sido el gofrado. Los nervios están decorados con un filete gofrado a cada uno de sus lados. La cabezada superior está decorada con el alternado de hilos de seda de colores naranja y crema.

IV. Estado de conservación: Su estado general es bueno, con restos de cinco bollones, uno en el centro y el resto en las esquinas de las dos tapas, también se ha perdido de la cabezada inferior por querer extraer el libro tirando de ella, pérdida de la guarda volante de pergamino posterior y agujeros en la parte superior de ambas tapas, posiblemente de un broche, que se ha perdido por el uso.

Autor: Odofredo Denari

Título: [Comentario sobre el Código de Justiniano], copia realizada en el siglo XV.

La encuadernación estudiada a continuación fue realizada en el siglo XV muy posiblemente por un artesano toledano, pertenece actualmente al Antiguo Fondo Toledano, sus dimensiones son 458 X 315 X $63 \mathrm{~mm}$. y su signatura es BCT 40-8.

I. Materiales empleados: Las tapas son de madera recubiertas de piel de color marrón, al igual que el lomo; las guardas son de pergamino; los entrenervios están recubiertos por papel verjurado con el título rotulado de forma manuscrita; aparecen refuerzos de pergamino en el lomo y en las guardas; los nervios son de tiras de badana curtida al alumbre; el núcleo de las cabezadas es de tiras de badana curtida al alumbre rodeado de hilo, y recubierto de hilos de seda de colores verde y naranja; los broches son de metal, las manecillas de piel marrón y las puntas de metal.

II. Técnicas de construcción: El cuerpo del libro está unido a las tapas mediante cinco nervios hendidos de tiras de piel curtida al alumbre, con un cosido a punto seguido; el lomo está redondeado; las cabezadas, realizadas manualmente, están unidas a las tapas y a los cuadernillos.

III. Decoración:

III /1. Estructura decorativa: La estructura de las tapas es simétrica y se compone de diferentes orlas concéntricas, apareciendo un trabajo de lacería realizado por dos hilos que dan lugar a una cinta que se entrecruza en las dos últimas orlas, añadiendo que la última está dividida en dos cuadrados, conteniendo en su interior una estructura aspada. 


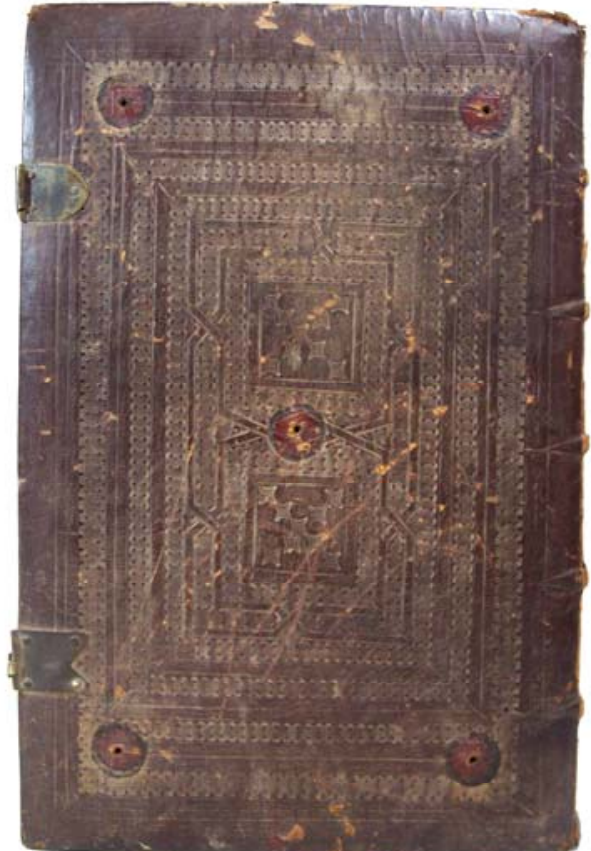

Figura 19. Tapa con do cuadrados en el centro.

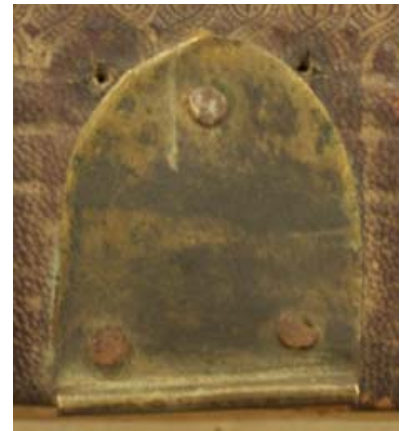

Figura 20. Broche de la tapa posterior.

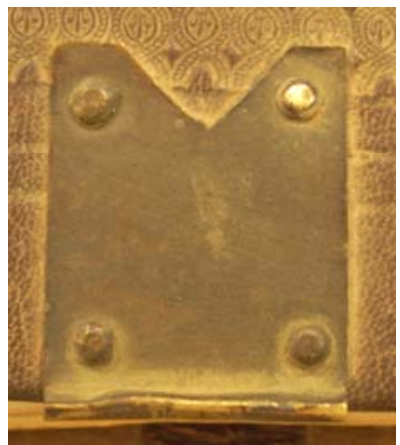

Figura 21. Broche de la tapa posterior.

III /2. Motivos decorativos: La decoración de la tapa anterior se inicia con un enmarcado exterior de tres filetes paralelos. La primera orla está decorada con lazos simples redondeados cordiformes con una pequeña flor de lis en su interior en la tapa anterior; a continuación, y sólo en la parte superior e inferior de las tapas, flanqueada por tres hilos paralelos, aparece una hilera de lazos simples redondeados cordiformes con una flor de lis en su interior en la tapa posterior, y lazos simples en ángulo cordiformes con una pequeña flor en el centro en la tapa anterior; el resto de las orlas están ornamentadas por lazos simples en ángulo cordiformes con una pequeña flor en el centro, a excepción de la tercera orla de la tapa posterior que está decorada con lazos simples redondeados cordiformes, también con una flor de lis en su interior. La entrecalle entre la primera y segunda orla está libre de decoración solo ornamentada con los tres hilos paralelos y un hilo que une las dos orlas; la entrecalle entre la segunda y tercera orla está libre de decoración sólo ornamentada con los dos hilos que la forman y un hilo que las une; entre la tercera y cuarta orla aparece un trabajo de lacería realizado por una cinta que se entrecruza; el centro de las tapas se divide en dos cuadrados formados por un encuadramiento de lazos simples en ángulo cordiformes con una pequeña flor en su interior seguida de dos hilos que dan lugar a dos cuadrados en cuyo interior aparecen, formado un aspa, ocho cuadrados de lados cóncavos con una flor en su interior en la tapa anterior y nueve en los cuadrados de la tapa posterior. Los utensilios empleados han sido 
hierros sueltos y la técnica decorativa utilizada ha sido el gofrado. Los entrenervios están recubiertos con un tejuelo con el título rotulado de forma manuscrita "Odofredi super Codice pars $2^{\circ}$. Las cabezadas están decoradas con el alternado de hilos de seda de colores verde y naranja. Los broches metálicos de la tapa anterior son diferentes aunque carecen de motivos decorativos, el superior tiene forma de punta curvada y el inferior cuadrangular.

IV. Estado de conservación: Su estado general es bueno, con restos de cinco bollones, uno en el centro y el resto en las esquinas de las dos tapas; también aparecen numerosas rozaduras producidas por los herrajes de las encuadernaciones cercanas.

Autor: Inocencio III (1198-1216), papa

Título: [Tratado de la miseria de la condición humana con el documento a los Confesores] mandada escribir por el Arzobispo de Toledo Alfonso Carrillo en el año de 1466.

La última encuadernación de lacería, con una estructura decorativa en la tapa anterior similar a las dos previas, fue realizada en el siglo XV, a partir de 1466, sus dimensiones son 223 X 172 X 45 mm., actualmente pertenece al Antiguo Fondo Toledano y su signatura es BCT 13-18.

I. Materiales empleados: Las tapas son de madera recubiertas de piel de color marrón oscura, al igual que el lomo el cual está revestido con papel verjurado con el título rotulado de forma manuscrita; las guardas son de papel verjurado con dos filigranas diferentes; los refuerzos en el lomo y en las guardas son de tela; los nervios son de tiras de piel; el núcleo de las cabezadas es de tiras de piel recubierto de hilo blanco; el broche es de metal y la tira de piel es de color marrón oscuro.

II. Técnicas de construcción: El cuerpo del libro está unido a las tapas mediante dos nervios hendidos de tiras de piel curtida al alumbre, con un cosido a punto seguido; el lomo es recto; las cabezadas, realizadas manualmente, son simples y están unidas a las tapas y a los cuadernillos; el corte delantero carece de ceja.

III. Decoración:

III /1. Estructura decorativa: La decoración no está realizada con precisión, resultando incluso bastante tosca. La estructura de las tapas no es simétrica y se compone de una orla concéntrica, que en la tapa anterior la divide en dos rectángulos, en cuyo interior se estampa otro rectángulo más pequeño; en el interior de la orla en la tapa posterior aparece estampado un gran rombo con una cruz en el centro.

III /2. Motivos decorativos: La decoración de la tapa anterior se inicia, con un enmarcado de cuatro filetes, en grupos de dos filetes, seguida de una orla formada por la repetición de rombos anudados cordiformes; esta orla divide la tapa en dos rectángulos, los cuales se forman mediante la repetición de crucetas de lazo cordiformes; el interior de los rectángulos está ornamentado, en el rectángulo superior por pequeños bastoncillos cordiformes rectos, y en el rectángulo inferior por crucetas de lazo cordiformes. 


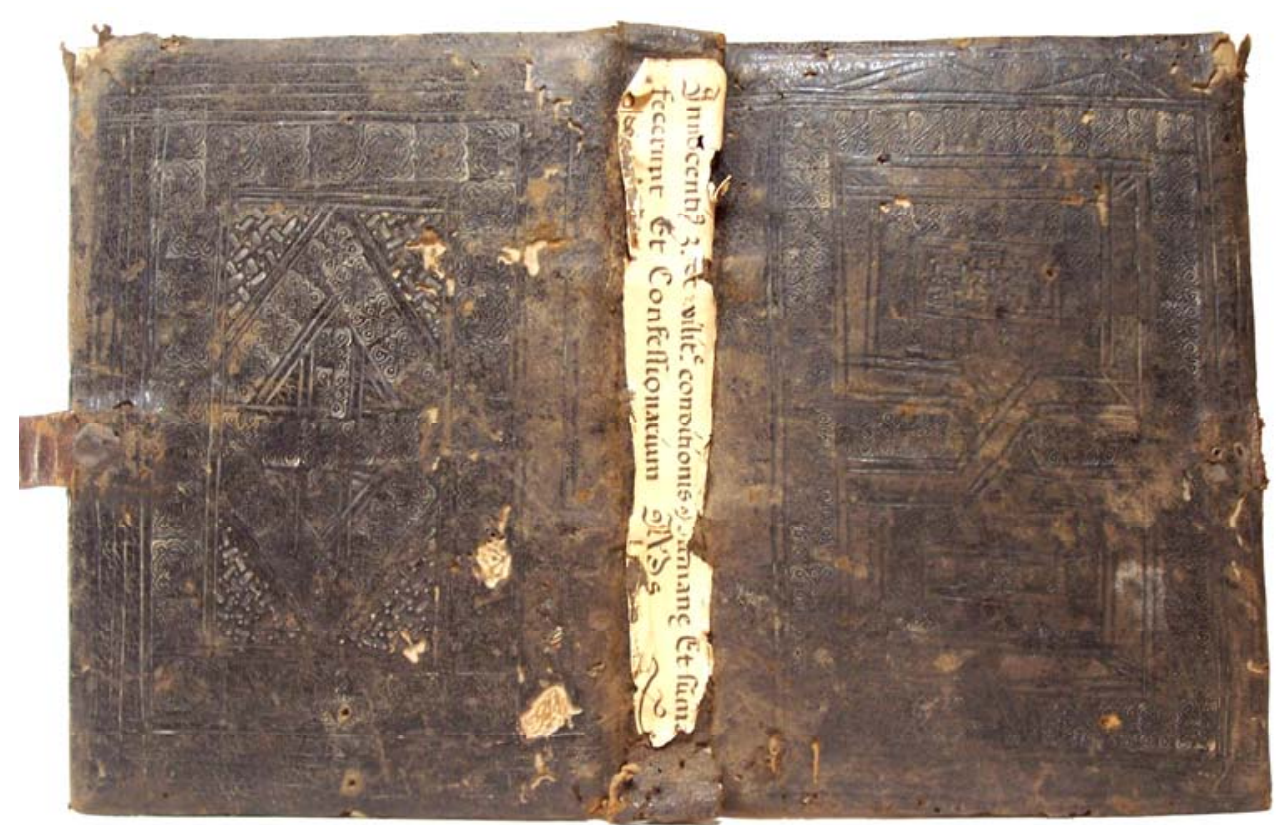

Figura 22. Tapa anterior y posterior.

La decoración de la tapa posterior se inicia con un enmarcado de seis filetes, en grupos de dos filetes, seguida de una orla formada por la repetición de rombos anudados cordiformes más grandes. El interior de la orla está ornamentado por un gran rombo formado por rombos anudados cordiformes, similares a los empleados en la orla de la tapa anterior; en el interior del rombo aparece una cruz formada por los mismos rombos anudados cordiformes. Los espacios libres de decoración, entre la orla y el rombo central están ornamentados por pequeños bastoncillos cordiformes rectos. Los utensilios empleados han sido hierros sueltos y la técnica decorativa utilizada ha sido el gofrado. Las guardas contienen dos filigranas diferentes con la similitud de que ambas tienen dos ruedas.

IV. Estado de conservación: Su estado no es bueno; en la parte inferior de la tapa posterior aparecen agujeros posiblemente de una cadena, además la encuadernación tiene pérdidas de piel en las puntas y en las cofias, y restos de insectos bibliófagos y manchas en las tapas.

\subsection{Estructura decorativa con dos rectángulos en el centro con figuras geométricas}

Las siguientes dos encuadernaciones continúan manteniendo dos rectángulos en cada plano, pero con el añadido de que diversas figuras geométricas, formadas por cintas, rodean cada rectángulo.

Autor: Santo Tomás de Aquino

Título: [Sobre el Libro IV de las Sentencias] ${ }^{11}$ Mss. de en el siglo XIV 
La obra está realizada sobre papel y pergamino con unas dimensiones de 415 X 285 mm., de la segunda mitad del siglo XIV, 343 folios, a dos columnas, capitales en morado y azul y la primera en oro. La encuadernación fue realizada en la primera mitad del siglo XV, forma parte del Antiguo Fondo Toledano, sus dimensiones son 434 X 303 X 112 $\mathrm{mm}$. y su signatura es BCT 19-3.

I. Materiales empleados: Las tapas son de madera y están recubiertas de piel de color marrón, al igual que el lomo; las guardas son de pergamino; los nervios son de tiras de badana curtida al alumbre; el núcleo de las cabezadas es de tiras de badana curtida al alumbre rodeado de hilo y recubiertos de hilos de seda de colores verde y naranja; los entrenervios están recubiertos de papel verjurado con el título rotulado de forma manuscrita; los broches son de tiras de piel y de metal.

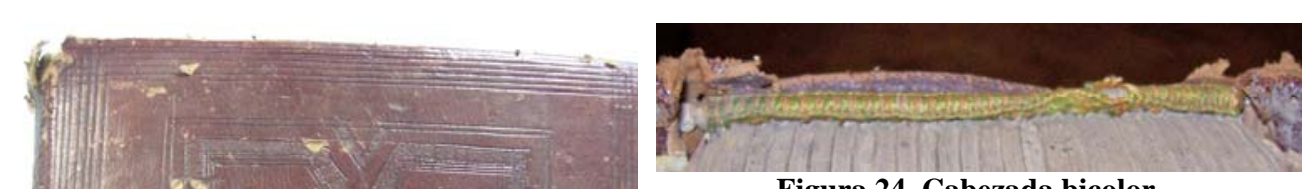

Figura 24. Cabezada bicolor.
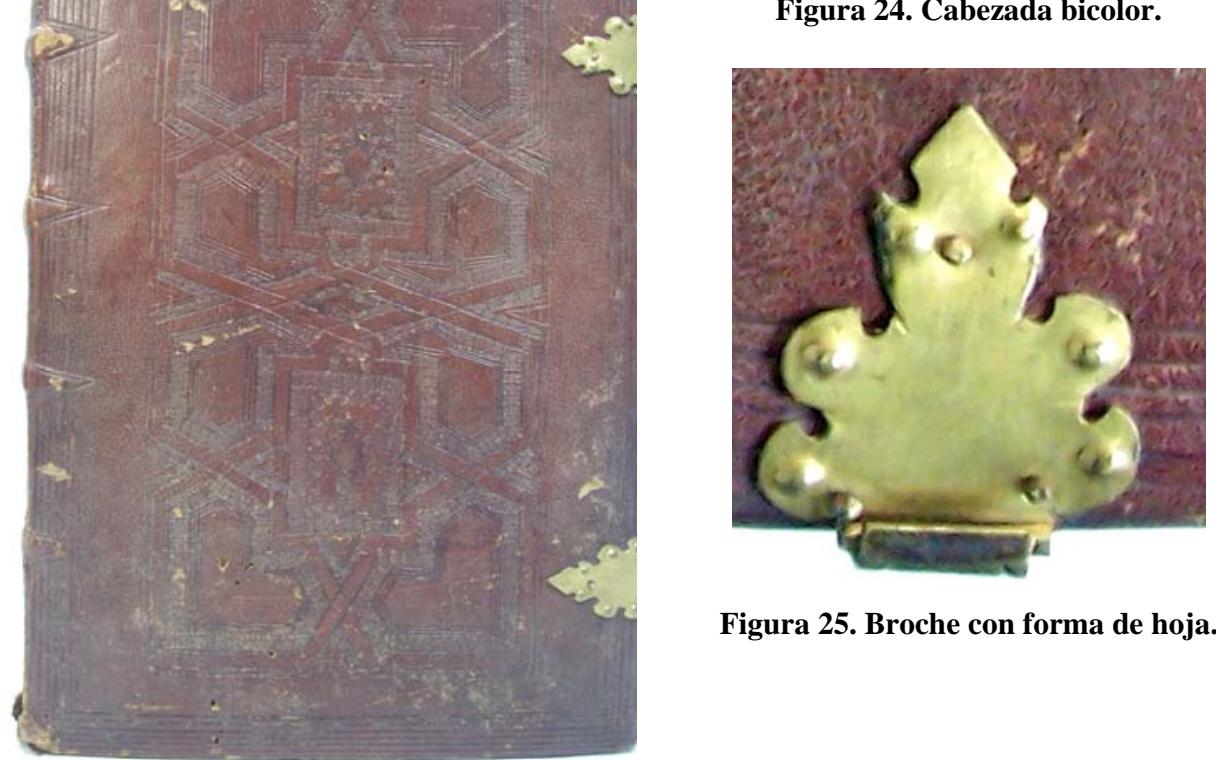

Figura 25. Broche con forma de hoja.

Figura 23. Tapa con dos rectángulos en el centro.

II. Técnicas de construcción: El cuerpo del libro está unido a las tapas mediante cuatro nervios hendidos de tiras de badana curtida al alumbre, con un cosido a punto seguido; el lomo está redondeado; las cabezadas, realizadas manualmente, están unidas a las tapas y a los cuadernillos.

III. Decoración: 
III /1. Estructura decorativa: La estructura de las tapas es simétrica y contiene un enmarcado exterior de siete filetes y un encuadramiento interior formado por cintas que se entrecruzan que dan lugar a dos rectángulos centrales.

III /2. Motivos decorativos: La decoración se inicia con un encuadramiento exterior de siete hilos; la ornamentación interior está formada por una cinta de dos hilos que se entrecruza formando diversos espacios decorados con lazos simples cordiformes redondeados con un pequeño punto en su interior y rodeados, hacia el interior, de tres hilos; los rectángulos centrales se forman con el mismo motivo de lazo simple redondeado $\mathrm{y}$ en su interior aparecen almenillas y un rombo formado con tres filetes y rodeado a su vez de almenillas. Los utensilios utilizados han sido florones y paletas y la técnica decorativa empleada ha sido el gofrado. Los nervios están ornamentados con pequeños hilos gofrados verticales. Los entrenervios están decorados con la estampación de hilos gofrados que han dado a una composición de pequeños rombos. Las cabezadas están decoradas con el alternado de hilos de colores verde y naranja. Los cierres metálicos tienen forma de hoja, y las manecillas de piel están decoradas, en su interior, con filetes gofrados.

IV. Estado de conservación: El estado es bueno, con algunos agujeros de broches o cadenas en la parte superior de las tapas.

Autor: Santo Tomás de Aquino

Título: [Suma teológica] copia realizada en el siglo XV; $1^{\mathrm{a}}, 2^{\mathrm{a}}$ duplicada en dos códices, el primero de folios de vitela y letra del siglo XIII con los índices de letra cursiva $\mathrm{y}$ de diversa mano, y el $2^{\circ}$ de papel de marca y letra del siglo XIV.

La encuadernación contiene un manuscrito realizado sobre papel, con unas dimensiones de 410 X $295 \mathrm{~mm}$., de la segunda mitad del siglo XIV, con 238 folios, a dos columnas, capitales en morado y azul. La encuadernación ha sido realizada en el siglo XV, pertenece al Antiguo Fondo Toledano, sus dimensiones son 430 X 305 X $80 \mathrm{~mm}$. y su signatura es BCT 19-9. Esta estructura decorativa es similar a la anterior con signatura BCT 19-3.

I. Materiales empleados: Las tapas son de madera recubiertas de piel de color marrón, al igual que el lomo; las guardas son de papel verjurado con una filigrana o marca de agua conocida como Corona; los entrenervios están recubiertos de papel verjurado con el título rotulado de forma manuscrita; los refuerzos son de papel con rotulado manuscrito en el lomo; los nervios son de tiras de piel curtida al alumbre; las cabezadas contienen un núcleo de tiras de piel curtida al alumbre, rodeadas de hilo de lino recubiertos de hilos de seda de colores verde y naranja; los broches son de tiras de piel y de metal.

II. Técnicas de construcción: El cuerpo del libro está unido a las tapas mediante cuatro nervios dobles de tiras de piel curtida al alumbre, con un cosido a punto seguido; el lomo está redondeado; las cabezadas, realizadas manualmente, están unidas a las tapas y a los cuadernillos. 


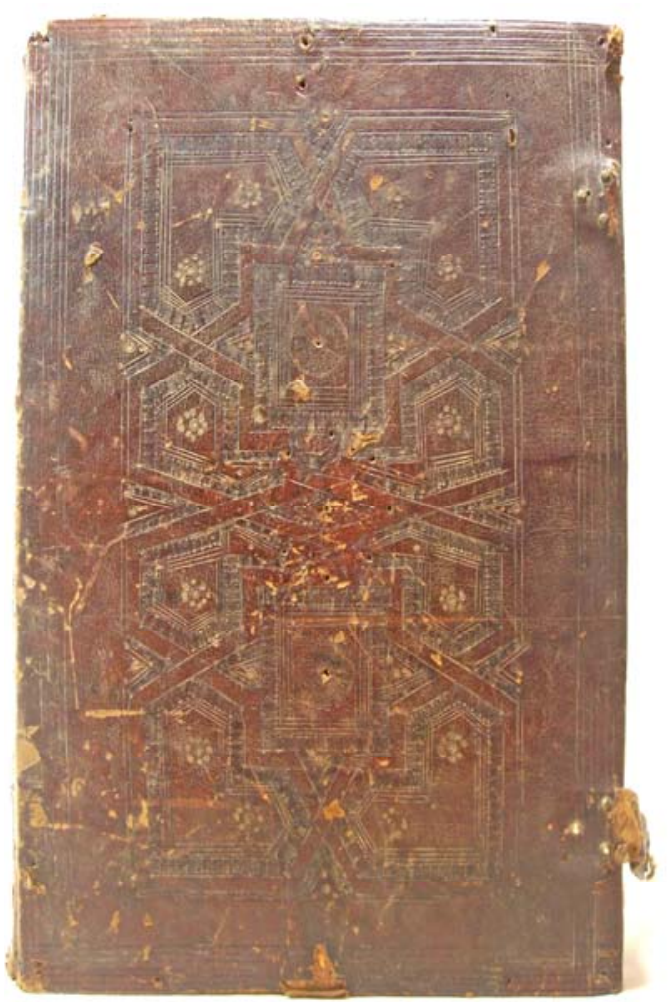

Figura 26. Tapa con dos cuadrados en su interior.

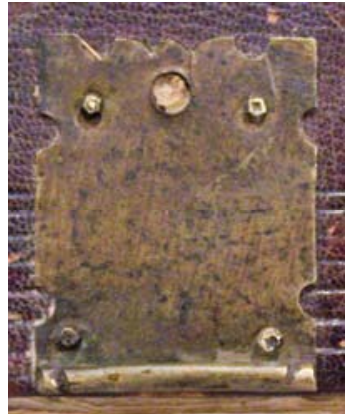

Figura 27. Broche de la tapa.

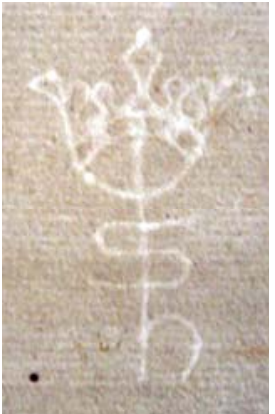

Figura 28.

Filigrana conocida como Corona.

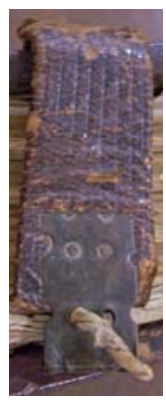

Figura 30. Manecilla de piel y punta de metal.

\section{Decoración:}

III /1. Estructura decorativa: La estructura de las tapas es simétrica y se compone de un trabajo de lacería que da lugar a dos estrellas de ocho puntas en el centro de ambas tapas.

III /2. Motivos decorativos: La decoración se inicia con un enmarcado exterior formada por siete hilos. La ornamentación central está formada por el entrecruzado de una cinta de dos hilos. El relleno del trabajo de lacería está compuesto de lazos simples redondeados y de tres filetes, y en la parte central ocho pequeños circulillos, algunos con restos de pintura roja, que rodean otro círculo doble algo más grande. El interior de las estrellas está decorado con lazos simples redondeados y un rectángulo de cuatro filetes. Los utensilios empleados han sido hierros sueltos y las técnicas decorativas utilizadas han sido el gofrado y la policromía. Los entrenervios están decorados con hilos gofrados que se entrecruzan formando pequeños rombos. El broche metálico está decorado con un pequeño agujero en el centro y la manecilla de piel está decorada, en su parte exterior, por 
ocho filetes verticales. Las hojas de respeto contienen una filigrana con una corona y unas iniciales, que según Briquet ${ }^{12}$, es italiana de 1465 con el $\mathrm{n}^{\circ}$ de inventario 4846. Las cabezadas están decoradas con el alternado de hilos de seda de colores verde y naranja.

IV. Estado de conservación: Su estado no es bueno, con agujeros de bollones pequeños en las esquinas, tres grandes en el centro y en las cantoneras de ambas tapas; también aparecen agujeros de cadena en la parte superior de las dos tapas. Se ha perdido la tira de piel del broche superior y de la parte de metal en el broche inferior, debido al mal uso.

\subsection{Estructura decorativa con tres rombos}

Las dos siguientes encuadernaciones disponen de una estructura decorativa similar compuesta de una ornamentación central de lacerías que forman tres rombos.

\section{Autor: Santo Tomás de Aquino}

Título: [Suma teológica] copia realizada en el siglo XIV.

La primera de estas encuadernaciones contiene una obra sobre papel con las dimensiones 304 X 220 mm., con 246 folios, a dos columnas, capitales en rojo y azul. La encuadernación fue realizada a finales del siglo XV, en la actualidad pertenece al Antiguo Fondo Toledano, sus dimensiones son 324 X 235 X 74 mm. y su signatura es BCT 19-5.

I. Materiales empleados: Las tapas son de madera recubiertas de piel de color marrón, al igual que el lomo el cual está revestido por papel verjurado con el título rotulado de forma manuscrita; las guardas son de papel verjurado; los nervios son de tiras de piel curtida al alumbre; las cabezadas contienen un núcleo de tiras de piel curtida al alumbre rodeadas de hilo de lino, recubiertos de hilos de seda de colores verde y naranja; los broches son de tiras de piel y metal.

II. Técnicas de construcción: El cuerpo del libro está unido a las tapas mediante seis nervios dobles de tiras de piel curtida al alumbre, con un cosido a punto seguido; el lomo está redondeado; las cabezadas, realizadas manualmente, están unidas a las tapas y a los cuadernillos.

III. Decoración:

III /1. Estructura decorativa: La estructura de las tapas es simétrica y se compone de un encuadramiento de filetes, una orla y un trabajo de lacería que da lugar a tres rombos en el centro de ambas tapas.

III /2. Motivos decorativos: La decoración se inicia con un encuadramiento formado por cinco filetes; la entrecalle está decorada con composiciones de cuatro círculos triples dorados o pintados, en forma de cruz, y dos en las esquinas; la orla está formada con curvas cordadas rodeada de pequeños circulillos dobles dorados o pintados. El encuadramiento central está compuesto de un trabajo de lacería formado por el entrecruzado de una cinta de dos hilos que da lugar a tres espacios en forma de rombos, los dos exteriores, con una de las puntas más alargada; los espacios vacios están decorados por lazos simples redondeados cordiformes y en el centro por bastoncillos rectos y curvos cordiformes y pequeños circulillos dobles y triples dorados o pintados; también aparecen círculos triples dorados o pintados distribuidos por el interior de la cinta. Los utensilios empleados han sido hierros sueltos y las técnicas decorativas utilizadas han sido el gofrado y el dorado o pintado. Los nervios y cada uno de los 
extremos de los entrenervios están decorados con diversos filetes horizontales gofrados. Los entrenervios están decorados con pequeños hierros bastoncillos rectos y curvos cordados mediante la técnica del gofrado. Las cabezadas están decoradas con el alternado de hilos de colores verde y naranja. Los broches de metal tienen forma de hoja y las manecillas de piel están gofradas por numerosos filetes verticales.

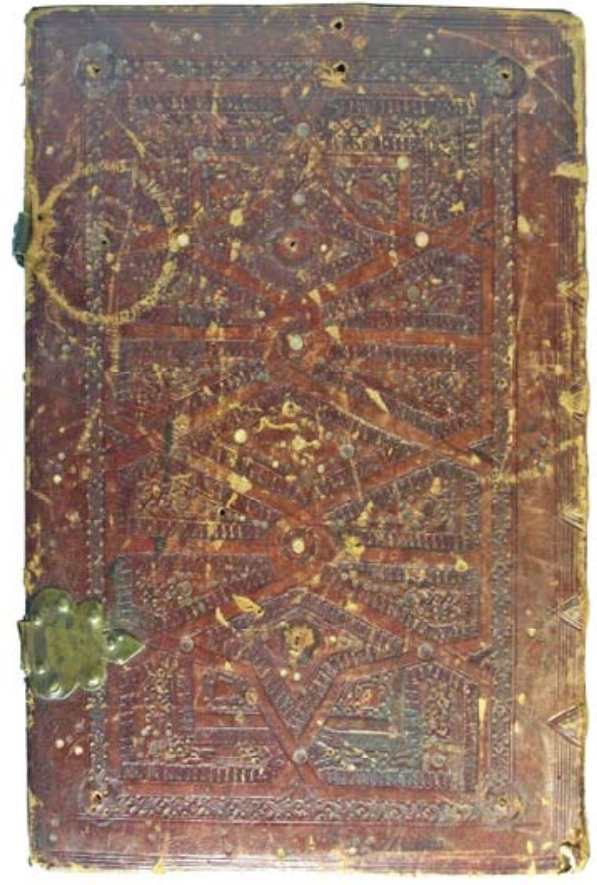

Figura 31. Tapa con tres rombos en su interior.

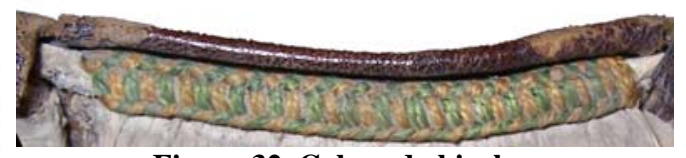

Figura 32. Cabezada bicolor.

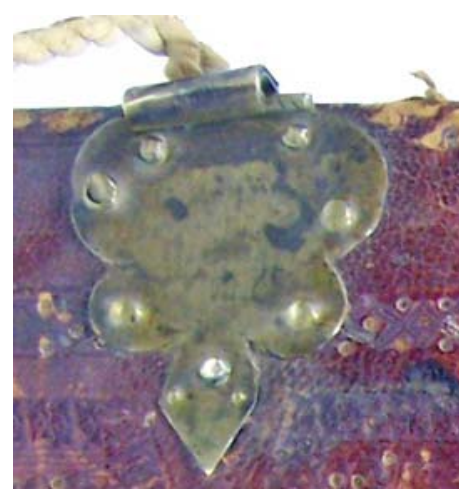

Figura 33. Broche con forma de hoja.

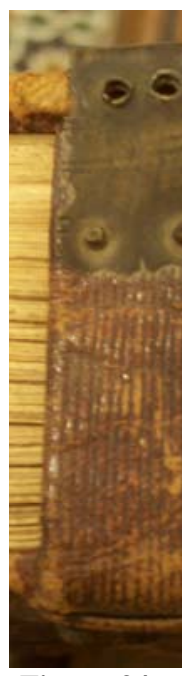

Figura 34. Manecilla de piel y punta de metal.

IV. Estado de conservación: Su estado destaca por las numerosas rozaduras de la piel, por los agujeros de bollones en ambas tapas y por los agujeros de cadena en la parte superior de la tapa posterior.

Autor: Pedro Martínez de Osma

Título: [In Ethicorum Aristotelis libros commentarii, correcti per rev. Magistrum de Roa cathedraticum in studio salmantino] de finales del siglo XV, con anterioridad a 1480.

La segunda encuadernación con lacerías que contiene tres rombos en el centro de las tapas fue realizada a finales del siglo XV, pertenece actualmente al Antiguo Fondo Toledano, sus dimensiones son 436 X 305 X $54 \mathrm{~mm}$. y su signatura es BCT 47-13. 
I. Materiales empleados: Las tapas son de madera recubiertas de piel de color marrón, al igual que el lomo; las guardas son de pergamino; las guardas volantes y las hojas de respeto son de papel verjurado con una filigrana o marca de agua conocida como Balanza, la cual está encerrada en un círculo ( 29 X $43 \mathrm{~mm}$.); los entrenervios están recubiertos por papel verjurado con el título rotulado de forma manuscrita los nervios son de tiras de badana curtida al alumbre; las cabezadas contienen un núcleo de tiras de badana curtida al alumbre, rodeadas de hilo y recubiertos de hilos de seda de colores verde y naranja; los broches son de metal y las manecillas de piel marrón y las puntas de metal.

II. Técnicas de construcción: El cuerpo del libro está unido a las tapas mediante siete nervios hendidos de tiras de badana curtida al alumbre, con un cosido a punto seguido; el lomo está redondeado; las cabezadas, realizadas manualmente, están unidas a las tapas y a los cuadernillos.

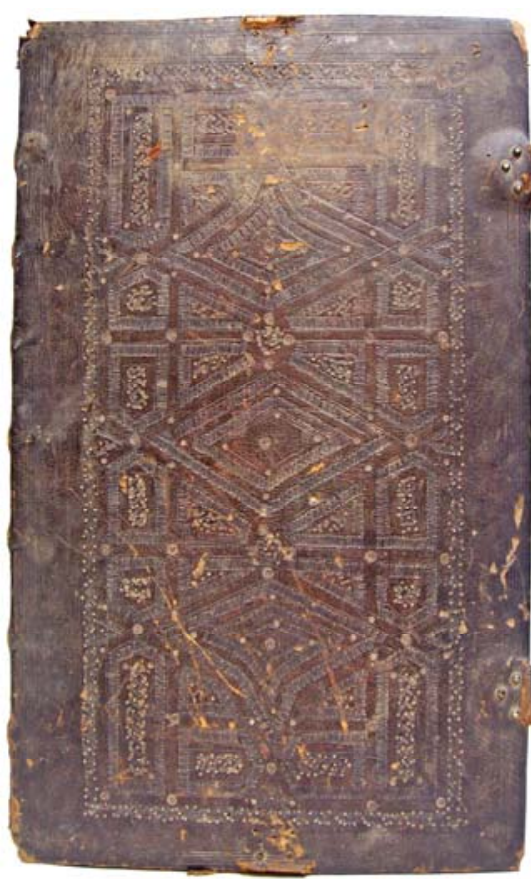

Figura 35. Tapa con tres rombos en su interior.

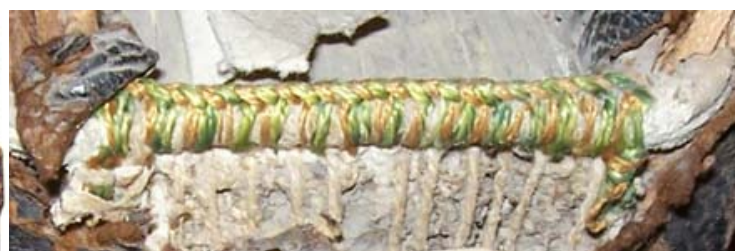

Figura 36. Cabezada bicolor.

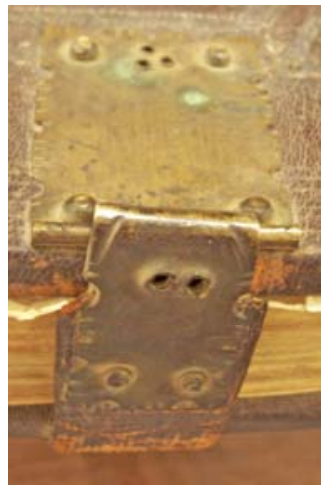

Figura 37. Puntas de metal.

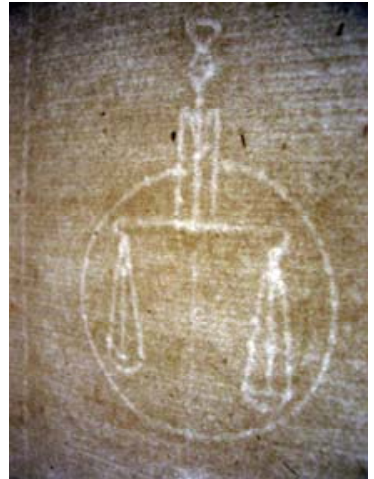

Figura 38. Filigrana conocida como Balanza.

\section{Decoración:}

III /1. Estructura decorativa: La estructura de las tapas es simétrica y se inicia con una orla seguida de un trabajo de lacería que da lugar a tres rombos en el centro de ambas tapas.

III /2. Motivos decorativos: La decoración comienza con un enmarcado concéntrica de cuatro filetes en la zona de la cabeza y pie y de nueve filetes en la zona de la delantera y 
lomo; la siguiente orla está formada con curvas cordadas rodeada de pequeños puntos. El encuadramiento central está compuesto de un trabajo de lacería formado por el entrecruzado de una cinta de dos hilos que dan lugar a tres espacios en forma de rombos, los dos exteriores, con una de las puntas más alargada; el espacio vacío está decorado por lazos simples redondeados cordiformes y en el centro por bastoncillos rectos y curvos cordiformes, pequeños circulillos dobles y triples dorados o pintados; también aparecen círculos triples dorados o pintados distribuidos por el interior de la cinta. Los utensilios empleados han sido hierros sueltos y las técnicas decorativas utilizadas han sido el gofrado y el dorado o pintado. Los nervios y cada uno de los extremos de los entrenervios están decorados con diversos filetes horizontales gofrados. Las cabezadas están decoradas con el alternado de hilos de colores verde y naranja. Las manecillas de piel de los broches están gofradas por numerosos filetes verticales. Las guardas contienen una filigrana conocida como Balanza, encerrada en un círculo, que según Briquet ${ }^{13}$ pudieron ser realizadas entre 1464 y 1482 tanto en ciudades italianas como alemanas.

IV. Estado de conservación: Su estado no es bueno y se caracteriza por las numerosas rozaduras en ambas tapas, la pérdida de broches en la cabeza y pie de ambas tapas y la falta de piel en las dos cofias.

\subsection{Estructura decorativa con dos hexágonos}

Autor: Tomás Valdense

Título: [Tratado de los Sacramentos contra los herejes] Mss.

El volumen siguiente contiene una estructura decorativa de lacerías con dos hexágonos en el centro de ambas tapas. La obra comienza desde el capítulo 96 del libro $2^{\circ}$, y acaba con el epílogo del libro $5^{\circ}$; la escritura es gótica cursiva; el manuscrito está realizado en papel de $151+1$ fol. a 2 columnas, con 50 líneas. La encuadernación fue realizada a mediados del siglo XV y pertenece actualmente al Antiguo Fondo Toledano, sus dimensiones son 420 X 295 X 64 mm. y su signatura es BCT 22-1.

I. Materiales empleados: Las tapas son de madera recubiertas de piel de color marrón, al igual que el lomo; las guardas son de papel verjurado con una filigrana conocida como Flor; los entrenervios están recubiertos de papel verjurado con el título rotulado de forma manuscrita; los nervios son de tiras de piel curtida al alumbre; las cabezadas contienen núcleo de tiras de piel curtida al alumbre, rodeadas de hilo de lino, y recubiertas de hilos de seda de colores verde y naranja; los broches son de metal.

II. Técnicas de construcción: El cuerpo del libro está unido a las tapas mediante cinco nervios hendidos de tiras de piel curtida al alumbre, con un cosido a punto seguido; las cabezadas, realizadas manualmente, están unidas a las tapas y a los cuadernillos.

III. Decoración:

III /1. Estructura decorativa: La estructura de las tapas es simétrica y se compone de dos orlas rectangulares y un rectángulo central con un trabajo de lacería.

III /2. Motivos decorativos: La ornamentación se inicia con un enmarcado exterior de cinco filetes, seguida de una orla, flanqueada por dos filetes a cada lado, de dos filas de rombos de lados cóncavos y pequeños bastoncillos cóncavos y rectos en los espacios vacíos. La segunda orla está formada por dos filas de lazos simples en ángulo cordiformes con una pequeña estrella en el centro, flanqueados por dos filetes a cada lado. El espacio 
central está decorado con un trabajo de lacería formado por una cinta de dos filetes que se va entrecruzando creando un trazado geométrico con dos hexágonos centrales. El relleno exterior del trabajo de lacería está ornamentado por lazos simples cordiformes redondeados, y el relleno interior, en la tapa anterior, por lazos simples cordiformes redondeados, y en la tapa posterior, por rombos con una flor de lis en su interior. Las entrecalles están vacías de decoración. Los utensilios empleados han sido hierros sueltos y la técnica decorativa utilizada ha sido el gofrado. Los nervios están decorados con un filete gofrado horizontal que acentúa la división del nervio hendido, y los entrenervios están decorados con el entrecruzado de hilos gofrados que dan lugar a una composición de pequeños rombos. Las cabezadas están decoradas con el alternado de hilos de seda de colores verde y naranja. Los cuatro broches de metal, dos en la delantera, uno en la cabeza y otro en el pie de la tapa posterior, disponen de tres agujeros, dos a los lados del broche y otro en su parte interior.

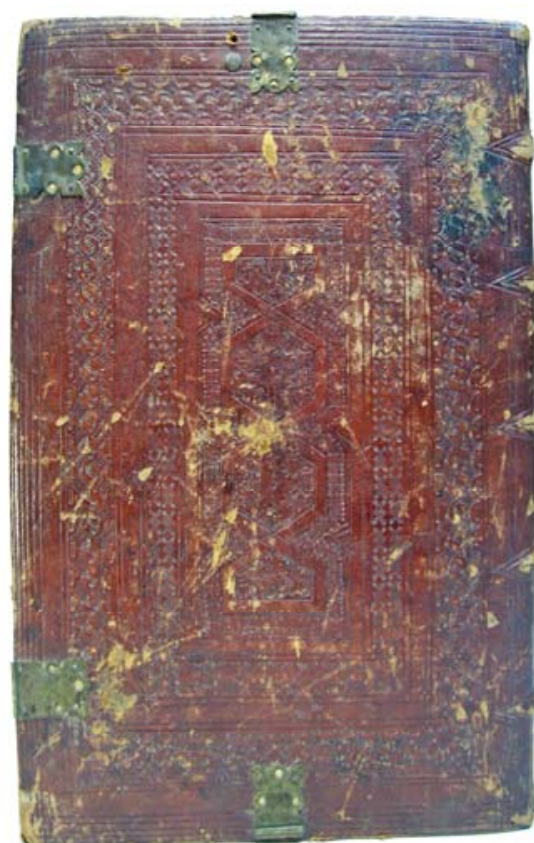

Figura 39. Tapa con dos hexágonos en el centro.

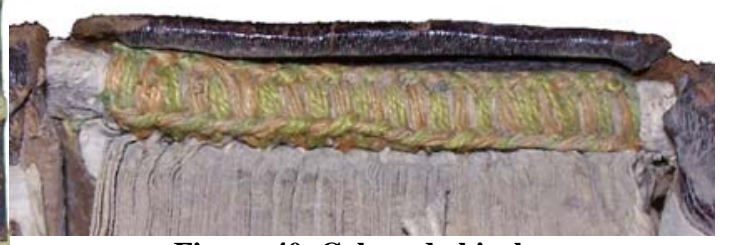

Figura 40. Cabezada bicolor.

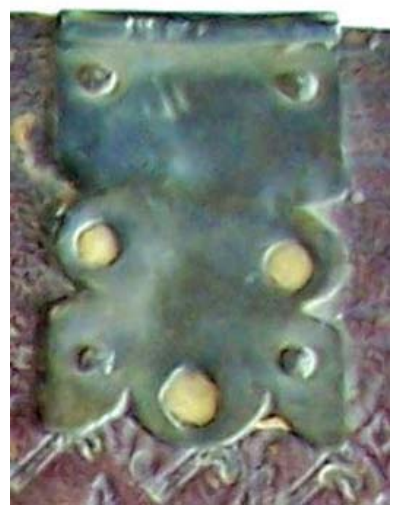

Figura 41. Broche.

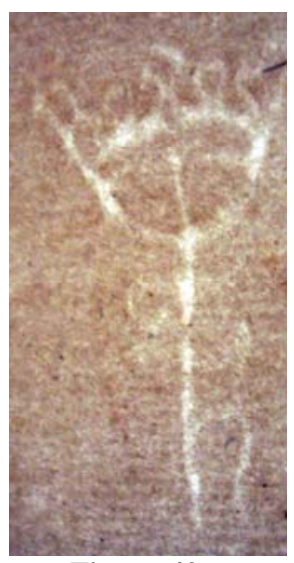

Figura 42. como Flor.

IV. Estado de conservación: Su estado no es bueno ya que las tapas contienen numerosas rozaduras y pérdida de las manecillas de piel de los broches. 


\subsection{Estructura decorativa con multitud de rombos}

Autor: Avicena (nombre latino por el que se conoce en la tradición occidental a Abū 'Alī al-Husayn ibn 'Abd Allāh ibn Sīnā, ca. 980-1037), médico, filósofo y científico persa que escribió cerca de cuatrocientos cincuenta libros sobre diferentes temas, predominantemente de filosofía y medicina.

Título: [Cinco partes de las obras de Avicena] Mss. Obras traducidas del árabe al latín por Gerardo Cremonense o de Cremona (1114-1187, posiblemente en Toledo) uno de los traductores más prolíficos de la Edad Media con casi cerca de setenta obras traducidas del árabe al griego y al latín.

La última encuadernación con una estructura decorativa de lacerías corresponde a una copia realizada en el siglo XIV, con 485 hojas de pergamino con el texto a dos y cuatro columnas; la obra presenta anotaciones marginales, de diferentes manos, las primeras iniciales de los cinco libros están bellísimamente miniadas con escenas y figuras alusivas al texto, en oro y colores, formando una orla al borde de toda la página. Hay un folio en blanco, sin numerar, al principio y al fin. La encuadernación es del XV realizada en Toledo, pertenece actualmente al Antiguo Fondo Toledano, sus dimensiones son 493 X 330 X $150 \mathrm{~mm}$. y su signatura es BCT 47-19.

I. Materiales empleados: Las tapas son de madera recubiertas de piel de color marrón, al igual que el lomo; las guardas son de pergamino; los entrenervios están recubiertos por papel verjurado con el título rotulado de forma manuscrita; los nervios son de tiras de piel marrón; las cabezadas contienen un núcleo de tiras de badana curtida al alumbre rodeadas de hilo; los broches son de metal.

II. Técnicas de construcción: El cuerpo del libro está unido a las tapas mediante seis nervios hendidos de tiras de piel curtida al alumbre, con un cosido a punto seguido; el lomo está redondeado; las cabezadas, realizadas manualmente, están unidas a las tapas y a los cuadernillos.

III. Decoración:

III /1. Estructura decorativa: La estructura de las tapas es simétrica y se compone de una orla exterior y un rectángulo central dentro del cual se realiza un trabajo de lacería geométrico formándose numerosos rombos.

III /2. Motivos decorativos: La decoración se inicia con un encuadramiento de dos filetes, seguido de una orla concéntrica formada por lazos simples redondeados cordiformes con una flor de lis en su interior flanqueada por dos filetes a cada lado; a continuación aparece una entrecalle vacía de decoración que da lugar a un gran rectángulo central donde destaca un trabajo de lacería. Este trabajo está formado por dos filetes que dan lugar a una cinta que se entrecruza creando rombos; los cruces de las cintas están decorados por un pequeño cuadrado de lados cóncavos; el relleno está formado por lazos simples cordiformes en ángulo con una pequeña flor en el centro. Los utensilios empleados han sido hierros sueltos y la técnica decorativa utilizada ha sido el gofrado. Los nervios están ornamentados con una paleta de un filete gofrado en el centro, lo que acentúa la utilización de nervios hendidos. Los entrenervios están decorados con una paleta de un doble filete dispuesto de forma diagonal creando una gran aspa, y recubiertos de papel con el título rotulado de forma manuscrita "Avicenna". 


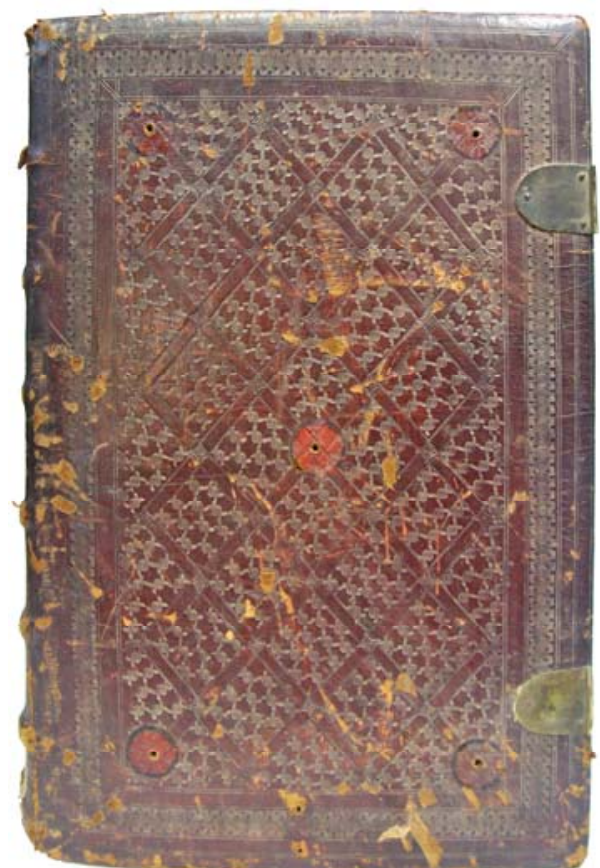

Figura 43. Tapa con multitud de rombos.

IV. Estado de conservación: Su estado es bueno, aunque aparecen algunos agujeros de bullones en las esquinas y centro de ambas tapas, también agujeros de cierres o cadena en la parte inferior de la tapa delantera y en la parte superior de la tapa trasera; además aparecen diversas rozaduras en las tapas debido a los herrajes de las encuadernaciones cercanas.

\section{ENCUADERNADORES}

En cuanto a los maestros ligatorios ${ }^{14}$ no hemos averiguado quién realizó cada obra, pero sí quienes pudieron ser los responsables, datos que hemos extraído de los libros de Obra y Fábrica de la catedral, incluso la firma de varios de ellos. En estos libros de Obra y Fábrica aparece el nombre de Maestre Arnao "librero" que realizó trabajos en los años 1425, 1426, 1427, 1428, 1529, 1431, 1432, Miguel Sánchez, racionero de la catedral (1425), Luis, "lector en la iglesia de Toledo" (1431), García Martínez, “capellán de la iglesia de Toledo" (1431), Juan González (1432), Pedro Sánchez, "cantor, escrivano de libros" (1432), Diego Sánchez, "librero" (1448), Sancho Rodríguez de Toledo, "librero" recibió pagos por encuadernaciones en los años 1453, 1454, 1457, 1458, 1459, 1461, 1463, 1475), Pedro, encuadernador (1475), Gonzalo Rodríguez también recibió pagos por encuadernaciones en los años 1493, 1495, 1498, 1500, 1501, 1503, 1504, 1506, 1507, 
1508, Manuel de Arévalo, clérigo (1501), Juan de Santa Catalina, librero recibió por parte de la catedral diferentes sumas de dinero por encuadernaciones realizadas a primeros del siglo XVI (1502, 1506, 1507, 1508), Juan Sánchez, librero (1504), Gonzalo de Ávila (1506), Fernando de Santa Catalina (1509, 1510, 1511), Francisco de Toledo (1512), Diego de Vera $(1514,1515,1517,1519)$ y Francisco de Vera (1516). Otro encuadernador de la época fue José de Esquivias que trabajó para el Cardenal Mendoza y para el Cabildo en 1483.

En ocasiones los encuadernadores también hacía trabajos de copista e iluminadores como es el caso de Luis, "cantor de la iglesia de Toledo", y de Pedro Sánchez; el hecho de que ambos sean clérigos con cierta relación a la catedral, y posiblemente con algún beneficio económico, nos hace pensar en que se trate de artesanos no profesionales que buscan otros ingresos, siendo estos casos excepcionales.

En esa época era muy habitual heredar el oficio de padres a hijos como es el caso de las profesiones relacionadas con el libro. Por ejemplo es muy posible que Juan y Fernando de Santa Catalina, encuadernadores, fueran padre e hijo respectivamente, y lo mismo los también encuadernadores Sancho y Gonzalo Rodríguez de Toledo y Diego y Francisco de Vera.

\section{CONSIDERACIONES FINALES}

Indicar que la mayoría de las encuadernaciones fueron realizadas en la primera mitad del siglo XV en un mismo taller toledano pues se emplean en la decoración una misma colección de motivos decorativos como lazos simples redondeados cordiformes con una flor de lis en su interior, lazos simples rectos cordiformes, rombos de lados cóncavos, peltas, así como cabezadas con las mismas estructuras e hilos de color verde y naranja. Además, también en varias encuadernaciones de la misma época coinciden las filigranas de los papeles de guardas que pertenecieron a la biblioteca privada del arzobispo Don Pedro Tenorio (1376-1399), aunque las encuadernaciones son posteriores.

En cuanto a los materiales empleados todas las tapas son de madera, las guardas son de pergamino y las hojas de respeto de papeles, en muchas ocasiones con filigranas de origen alemán o italiano. Los nervios y el alma de las cabezadas son de tiras de piel curtida al alumbre; el cosido se ha realizado con la técnica denominada como "a punto seguido", los lomos están redondeados y la técnica decorativa empleada en todas las tapas ha sido el gofrado.

\section{NOTAS}

${ }^{1}$ Este trabajo forma parte de los resultados obtenidos dentro del Proyecto de Investigación Santander/CentralComplutense titulado Las encuadernaciones de la Catedral de Toledo: catalogación y difusión ${ }^{1}$ (PR41/0614969), para el periodo 2007-2008 y finalizado en junio de 2009 y de las líneas de investigación de Grupo BIBLIOPEGIA: grupo de investigación sobre encuadernación y el libro antiguo (941369) de la Universidad Complutense de Madrid. En este proyecto de investigación han participado Antonio Carpallo Bautista, como 
investigador principal, Adelina Clausó García, Esther Burgos Bordonau, Ana Belén Sánchez Prieto, Arsenio Sánchez Hernampérez y Juan Antonio Yeves Andrés como investigadores.

2 Técnica de decoración de la piel, sin calor y con humedad, que consisten en estampar un hierro por golpe o presión. También denominada estampación en frío.

3 Técnica de estampación de la piel, con calor y con humedad, que consisten en estampar un hierro o plancha por golpe o presión. También denominada estampación en seco.

${ }^{4}$ López Serano, Matilde. La encuadernación española: breve historia. Madrid: ANABA, 1972, 146 p.

5 Álvaro Zamora, I. "Encuadernaciones mudéjares". Artigrama, nº 23, 2008, 445-481.

${ }^{6}$ Méndez Aparicio, Julia. La encuadernación mudéjar. Encuadernaciones españolas en la Biblioteca Nacional. Madrid: Biblioteca Nacional: Ollero \& Ramos, 1992, p. 17-30.

${ }^{7}$ Hueso Rolland, Francisco. Exposición de encuadernaciones españolas: siglos XII al XIX. Madrid: Sociedad Española de Amigos del Arte, 1934, 254 p.

8 Miquel y Planas, Ramón. Restauración del Arte hispano-árabe en la decoración exterior de los libros. Barcelona: Casa Miquel-Rius, 1913, 23 p., lám. XXI.

${ }^{9}$ Ainaud Lasarte, Juan. Encuadernación. Ars Hispaniae. Madrid: Plus Ultra, 1962, vol. XVIII, p. 321-344.

${ }^{10}$ Esta encuadernación formó parte de la exposición Las encuadernaciones artísticas de la Catedral de Toledo, celebrada en la Capilla de Reyes Nuevos de la Catedral entre el 10 de junio al 30 de septiembre de 2009.

${ }^{11}$ La obra en su interior contiene una inicial iluminada identificada por Jesús Domínguez Bordona en su obra Manuscritos con pinturas, Tomo II, publicado en Madrid en 1933, p. 198.

${ }^{12}$ Briquet, Ch. Les filigranes. Dictionaire historique des marques du papier de leur apparition vers 1282 jusq' 1600. New York, 1985.

${ }^{13}$ Briquet, Ch. Op. Cit.

${ }^{14}$ Todos estos datos sobre los encuadernadores han sido proporcionados por la profesora Ana Belén Sánchez Prieto, profesora de la Facultad de Ciencias de la Documentación de a UCM, miembro del Bibliopegia: grupo de investigación sobre encuadernación y el libro antiguo de la UCM y miembro del proyecto de investigación que ha catalogado y digitalizado las encuadernaciones artísticas de la Catedral de Toledo.

\section{BIBLIOGRAFÍA}

AINAUD LASARTE, J. Encuadernación. En Ars Hispaniae. Madrid: Plus Ultra, 1962, vol. XVIII, p. 321-344.

ÁLVARO ZAMORA, I. Encuadernaciones mudéjares. Artigrama, 2008, nº 23, p. 445481.

CARPALLO BAUTISTA, A. Estudio de las encuadernaciones del siglo XV de la Biblioteca Complutense. Gutenberg Jahrbuch, 2009, p. 315-345.

HUESO ROLLAND, F. Exposición de encuadernaciones españolas: siglos XII al XIX. Madrid: Sociedad Española de Amigos del Arte, 1934.

LÓPEZ SERANO, M. La encuadernación española: breve historia. Madrid: ANABA, 1972.

MÉNDEZ, V. Encuadernación mudéjar: desarrollo geométrico de la lacería. Noticias bibliográficas, 1994, nº 40, p. 5-11.

MÉNDEZ APARICIO, J. La encuadernación mudéjar. En Encuadernaciones españolas en la Biblioteca Nacional. Madrid: Biblioteca Nacional: Ollero \& Ramos, 1992, p. 1730.

MIQUEL Y PLANAS, R. Restauración del Arte hispano-árabe en la decoración exterior de los libros. Barcelona: Casa Miquel-Rius, 1913. 